\title{
Is small smarter? Nanomaterial-based detection and elimination of circulating tumor cells: current knowledge and perspectives
}

This article was published in the following Dove Medical Press journal: International Journal of Nanomedicine

\author{
Alena Gribko' \\ Julian Künzel' \\ Désirée Wünsch' \\ Qiang Lu' \\ Sophie Madeleine Nagel' \\ Shirley K Knauer ${ }^{2}$ \\ Roland H Stauber ${ }^{1}$ \\ Guo-Bin Ding ${ }^{1,3}$
}

'Nanobiomedicine Department/ ENT, University Medical Center Mainz, Mainz 55। 3 I, Germany; ${ }^{2}$ Department of Molecular Biology II, Center for Medical Biotechnology (ZMB)/Center for Nanointegration (CENIDE), University Duisburg-Essen, Essen 45 II7, Germany; ${ }^{3}$ Institute of Biotechnology, Key Laboratory of Chemical Biology and Molecular Engineering of Ministry of Education, Shanxi University, Taiyuan 030006, People's Republic of China
Correspondence: Roland H Stauber; Guo-Bin Ding

Nanobiomedicine Department/ENT, University Medical Center Mainz,

I Langenbeckstrasse, Mainz 55I3I, Germany

Tel +49 6I3 II7 7002; +49 6I3 II76030 Email roland.stauber@unimedizin-mainz. de; dinggb2012@sxu.edu.cn

\begin{abstract}
Circulating tumor cells (CTCs) are disseminated cancer cells. The occurrence and circulation of CTCs seem key for metastasis, still the major cause of cancer-associated deaths. As such, CTCs are investigated as predictive biomarkers. However, due to their rarity and heterogeneous biology, CTCs' practical use has not made it into the clinical routine. Clearly, methods for the effective isolation and reliable detection of CTCs are urgently needed. With the development of nanotechnology, various nanosystems for CTC isolation and enrichment and CTC-targeted cancer therapy have been designed. Here, we summarize the relationship between CTCs and tumor metastasis, and describe CTCs' unique properties hampering their effective enrichment. We comment on nanotechnology-based systems for CTC isolation and recent achievements in microfluidics and lab-on-a-chip technologies. We discuss recent advances in CTC-targeted cancer therapy exploiting the unique properties of nanomaterials. We conclude by introducing developments in CTC-directed nanosystems and other advanced technologies currently in (pre)clinical research.
\end{abstract}

Keywords: liquid biopsy, cancer biomarker, metastasis, nanomedicine, nanotherapy, therapy resistance

\section{Introduction}

The relevance and currency of a scientific topic can be judged by examination of available databases. Searching PubMed using the search criteria "nanotechnology" AND "CTCs", "nano" AND "CTCs", and "nano" AND "circulating tumor cells" reveals 131 reports published between 2009 and 2018 (current status May 2018). As illustrated in Figure 1, the number of published reports has increased nearly fivefold over the last 6 years. These results are almost expected, because of the steadily growing application of engineered nanomaterials (NMs) in biotechnology and biomedicine. ${ }^{1}$ One of the preferential areas in which nanomedicine will play a vital role is the early diagnosis and efficient treatment of cancer.

The majority of cancer-related deaths are caused by cancer metastasis, accounting for about $90 \%$ of cancer mortality. ${ }^{2-5}$ Metastasis is a multistep process comprising the dissemination of cancer cells from primary tumors to distant tissue, which is also known as the invasion-metastasis cascade. Unfortunately, the detailed molecular mechanisms underlying tumor metastasis remain unclear, but it is known that one necessary step in distant metastasis is the transport of tumor cells through the blood system. ${ }^{6,7}$ Circulating tumor cells (CTCs) are cancer cells of solid-tumor origin that have detached into peripheral blood from a primary tumor and circulate in the body. CTCs are able to 


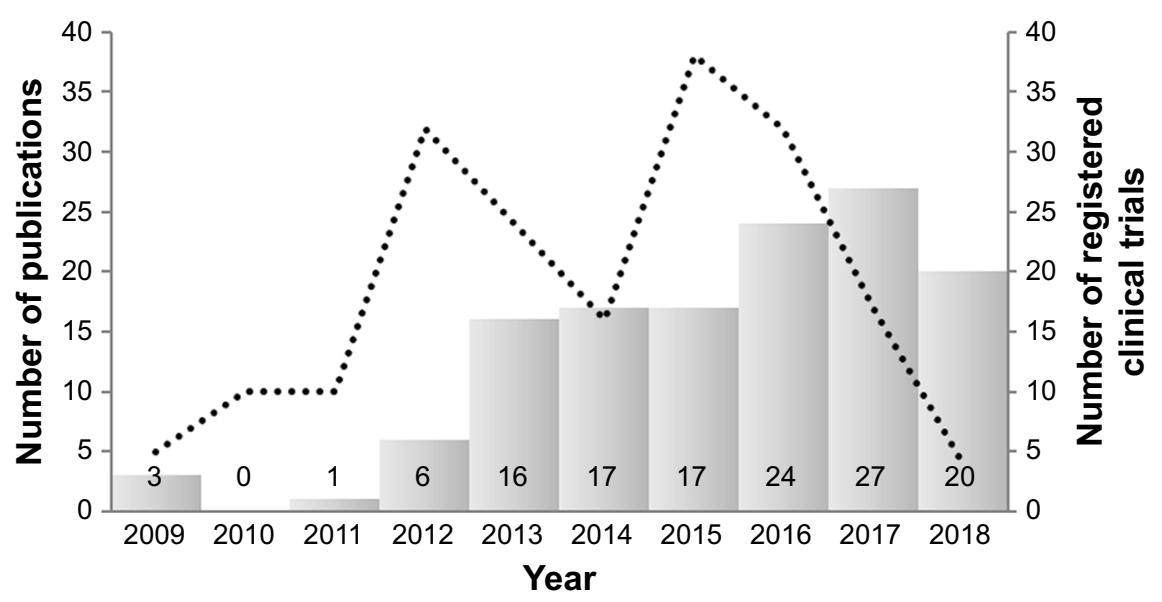

Figure I Timeline of PubMed entries.

Notes: Search criteria included "nanotechnology" AND "CTCs", "nano" AND "CTCs", and "nano" AND "circulating tumor cells" to determine number of publications (columns). Timeline of World Health Organization International Clinical Trials Registry Platform entries to display the number of registered clinical trials using search criteria "circulating tumor cells" AND "nano".

move as individual cells or as multicell clumps. During circulation, only a small number of CTCs extravagate and seed the growth of a secondary tumor. ${ }^{8}$ Therefore, detection and characterization of CTCs with liquid biopsy offer important information on prediction of cancer progression and survival after specific treatment. ${ }^{9}$ The number of detected CTCs usually correlates with the progression of cancer disease, so that a high number of CTCs give some indication of tumor burden and recurrence. ${ }^{10-12}$ Furthermore, enumeration of CTCs represents an attractive biomarker for monitoring therapeutic response and predicting the possibility of tumor recurrence. ${ }^{3}$ Cultures of patient-derived CTCs can be most helpful for drug-resistance detection, and make it possible for personalized anticancer-agent screening (Figure 2). ${ }^{10,13}$

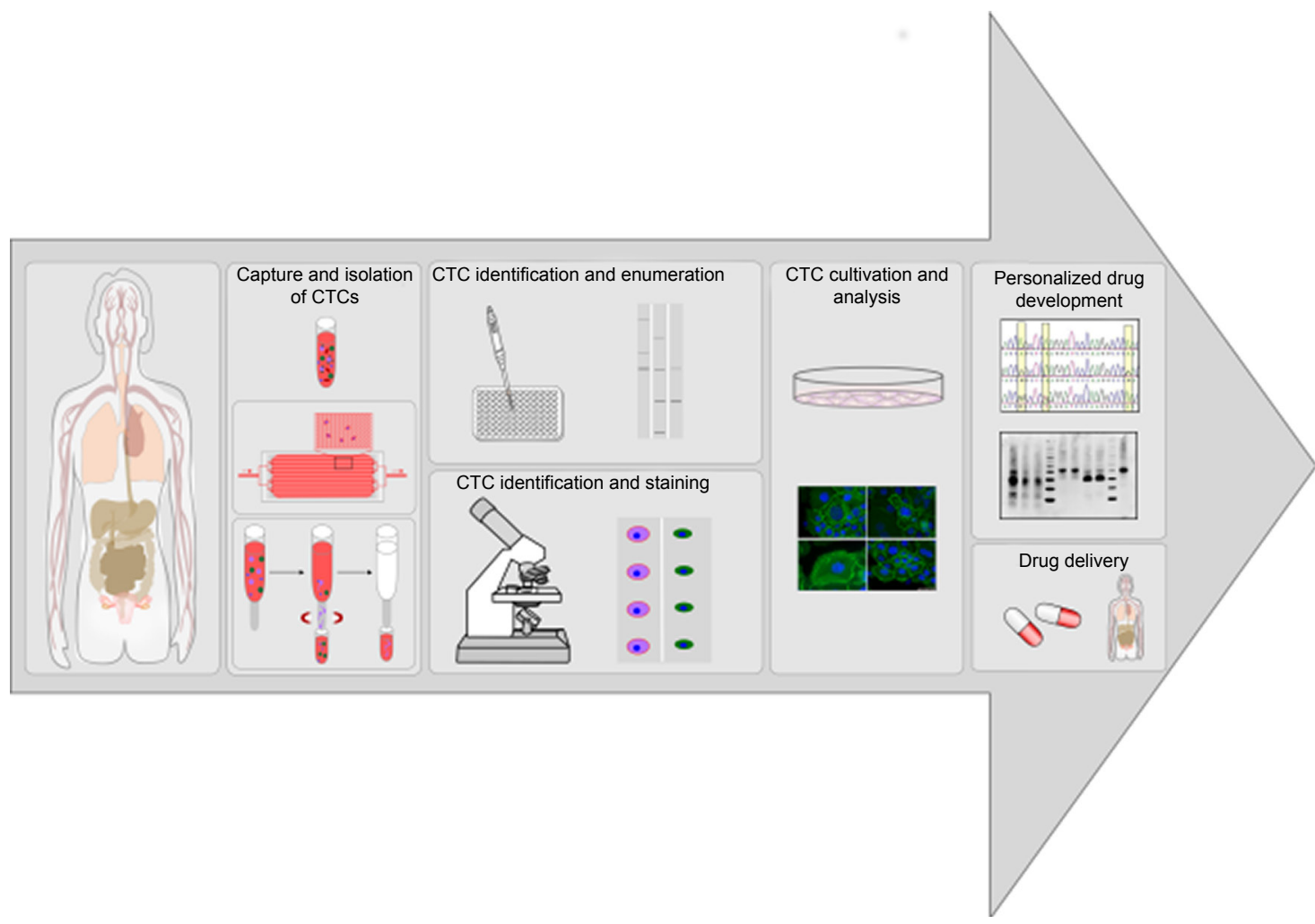

Figure 2 Workflow of patient-derived CTCs for CTC analysis, drug-resistance detection, and personalized drug-delivery systems.

Notes: Patients' blood samples are screened and potential CTCs captured and isolated. Potential CTCs can be enumerated, determined, and stained or cultivated for further analysis. CTC culture can be used for drug-resistance detection and personalized drug development, thereby increasing patient-survival rates.

Abbreviation: CTCs, circulating tumor cells. 
The detection of CTCs has been clinically recognized in many cancer types, including breast, ${ }^{14}$ colon, ${ }^{15}$ lung, ${ }^{16}$ melanoma, ${ }^{2}$ ovarian, ${ }^{17}$ and prostate cancers. ${ }^{18}$ Determination of the existence of CTCs in blood samples of patients during early stages of tumorigenesis is a significant biomarker for early cancer detection. ${ }^{19}$ However, because CTCs are very rare, their capture and detection are extremely challenging. Early-stage cancer patients have as few as one CTC in $1 \mathrm{~mL}$ blood, including approximately 5 billion red blood cells and 10 million white blood cells..$^{20,21}$ A further challenge is the heterogeneity of the circulating-cell population and their biological and molecular changes during the epithelialmesenchymal transition (EMT). ${ }^{22}$ Therefore, efficient isolation of CTCs also requires the ability to handle a very small number of cells.

Since the discovery of CTCs in 1869 by the Australian researcher Thomas Ashworth, a variety of important advancements in this area have been made only during the last two decades. ${ }^{23}$ A large number of isolation and detection techniques have been developed, and more than 100 companies are providing CTC-related products and services. ${ }^{24}$ As also illustrated in Figure 1, querying the WHO International Clinical Trials Registry Platform using the search criteria "circulating tumor cells" AND "*nano*" reveals that about 200 clinical trials have been registered over the last 13 years. The increase in the number of clinical trials mirrors the rising number of CTC/nanorelated publications and thus the growing scientific interest in this research area.

During the past several decades, a variety of advanced nanoscale materials, including metal, metal oxide, semiconductor, and polymeric NMs, have been developed and used in a wide range of areas, such as medicine, electronics, catalysis, and energy conversion and storage. ${ }^{20}$ NMs have made excellent contributions to clinical medicine, since they possess attractive properties related to their size, shape, and surface characteristics. ${ }^{25}$ Due to nanoscale effects, these exceptional structural and functional properties of NMs are typically different from either bulk materials or discrete molecules. In recent years, NMs have played an increasingly important role in CTC enrichment and detection. NMs offer a fundamental advantage for early CTC detection, obvious diagnosis, and personalized treatment of malignant tumors. ${ }^{26}$ Conjugation of NMs with targeting ligands could significantly improve the specificity in CTC recognition. NMs can also be used as drug-delivery systems for CTCtargeted drugs and cancer treatment. ${ }^{27}$ Furthermore, the large surface:volume ratio of NMs endows them with high cellular binding affinity in the complex blood matrix. Manipulation of NMs gives them the ability of multiplexed detection and targeting, which are crucial to approach the heterogeneous problem of CTCs. ${ }^{20}$

In this review, we elucidate the relationship between CTCs and tumor metastasis. An overview of current CTCenrichment strategies is also provided. We discuss the interactions of nanoparticles (NPs) with such biomolecules as proteins in biological media, and what consequences this may have on detection and isolation strategies. Literature on in vitro NP-based CTC-enrichment systems that has drawn extensive attention due to their clinical potential is also elaborated in this review. We also lay emphasis on microfluidic and lab-on-a-chip technologies for simultaneous CTC enrichment and analysis. Some CTC-detection and -analysis methods are briefly discussed as a guide for the development of potential clinical diagnostic platforms. Last but not least, we summarize research progress in the development of robust nanosystems for CTC-targeted cancer therapy.

\section{CTCs and metastasis}

As mentioned, cancer cells that detach from primary tumors followed by intravasation into the circulating system are often called circulating tumor stem cells, due to their stem-like properties. ${ }^{28}$ During early steps of the metastatic cascade, CTCs are involved in the process of EMT. ${ }^{29}$ This process is responsible for weakening cell-cell adhesion by downregulation of various cell adhesion molecules (eg, E-cadherin) or epithelial antigens (eg, epithelial cell adhesion molecule [EpCAM]). Due to specific signaling molecules (Wnt/ $\beta$-catenin, FGF, or TGF $\beta 1 / \mathrm{BMP}$ ), EMT initiates the migration for transfer of epithelial-like cells into mesenchymal-like cells. ${ }^{30}$ These characteristics of EMT lead to the detachment of CTCs from primary tumors, infiltration of the blood circulation, and arrival at distant sites of future metastasis (Figure 3). ${ }^{7,31}$ At distant sites, metastatic colonization is regulated by interactions of CTCs with the local microenvironment. The new microenvironment leads to adaptation processes of the CTCs via a large number of developmental and self-renewal signaling pathways, such as Hh, Wnt, and Notch, initiating proliferation and finally seeding to form metastases. ${ }^{32}$ To resettle in the target organ, CTCs need to recover their epithelial characteristic, a process known as mesenchymal-to-epithelial transition, the reverse process of EMT. ${ }^{33}$ The EMT process is necessary for the initiation of a stem-cell phenotype that exhibits such characteristics as self-renewal ability, high invasiveness, and resistance to apoptosis and therapy. ${ }^{34,35}$ Some of these characteristics developed during the metastasizing process are used as biomarkers for detection and isolation of CTCs, as discussed in the following section. 


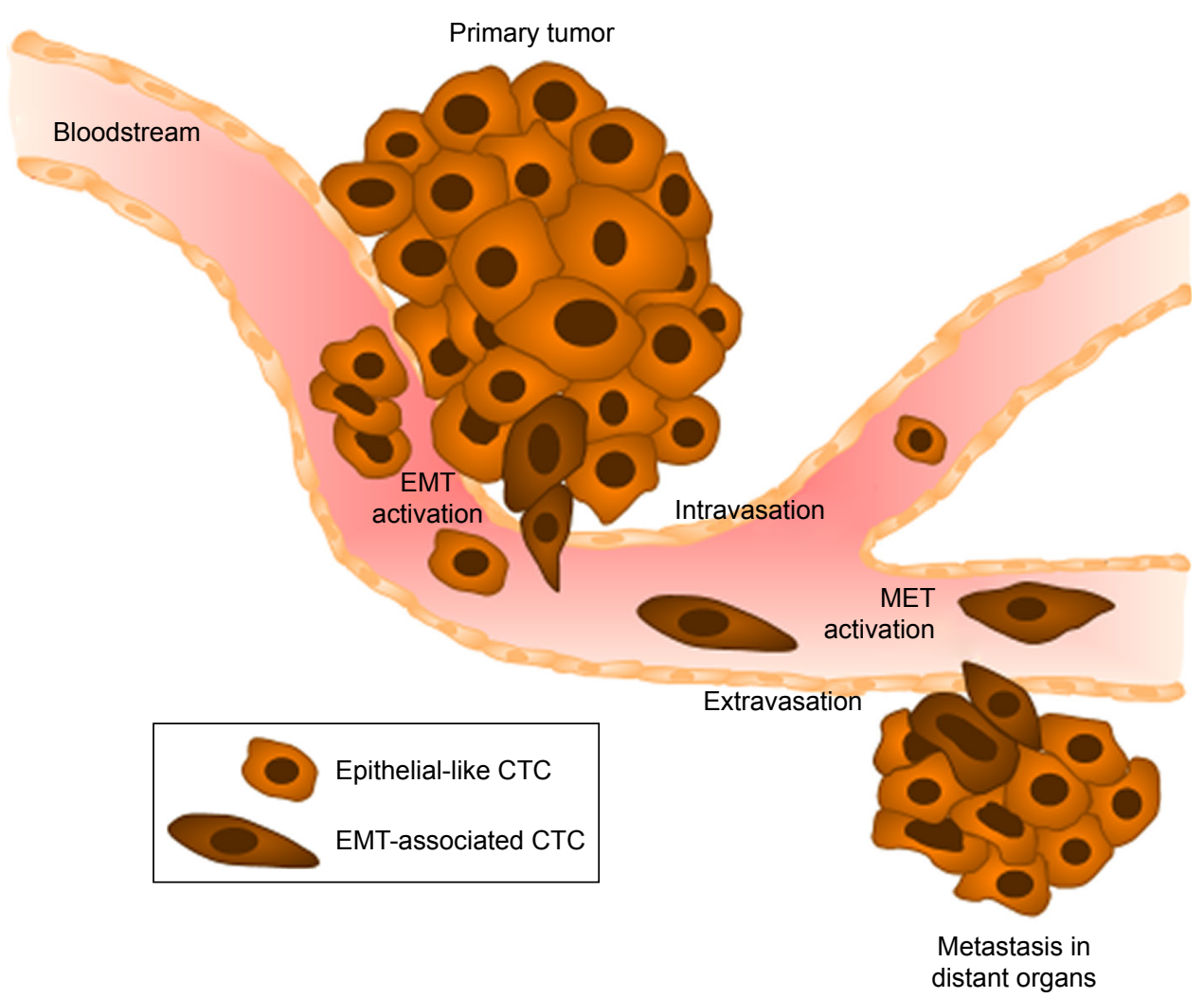

Figure 3 Characteristic stages of tumor-cell dissemination during metastasis.

Notes: Cells from primary tumors undergo epithelial-mesenchymal transition (EMT), leading to the loss of cell-cell adhesion and promoting local invasion into the blood vessels (intravasation). The CTCs produced are able to escape from blood vessels into distant organs of future metastasis (extravasation) after the reverse process (MET), induced by interaction with the local microenvironment.

Abbreviations: CTCs, circulating tumor cells; MET, mesenchymal-to-epithelial transition.

\section{Biological characteristics of CTCs as biomarkers for detection and isolation}

Effective capture and accurate identification of CTCs require a high level of sensitivity, as well as specificity, due to the extreme rarity and heterogeneous phenotypes of CTCs in the blood system. Some unique properties of CTCs can be employed to distinguish CTCs from surrounding normal hematologic cells and also for their enrichment and detection. ${ }^{27}$ Current CTC-enrichment methods are based on either physical properties (size, density, deformability, and electrical charge) or biological features (cell-surface protein expression, invasive capacity, and viability). ${ }^{36} \mathrm{Com}-$ monly used isolation methods based on physical properties include density-gradient centrifugation, membrane filtration, and microchip-based capture platforms. These methods are less specific, although they are fast, simple, and label-free. Therefore, "physical methods" are usually used in combination with the antibody-labeled biological method. Examples of biological characteristic-dependent isolation methods include immunomagnetic separation and substrate- and microchip-based capture platforms. ${ }^{20}$

For most biological detection methods, specific cancer biomarkers are indispensable. Cancer biomarkers are the measurable molecular changes between normal and cancerous tissue of patients. Each cancer type has specific molecular characteristics and pathological evolution. As such, the identification of these biomarkers is important for further applications in CTC capture and isolation. ${ }^{37,38}$ For example, CTCs are commonly described to express EpCAM, cytokeratins, and to be nucleated (identified by staining with a nuclear dye, such as DAPI), but do not express the white blood-cell surface marker CD45. The use of HER2, vimentin, ALDH1, and CD44 is also common for CTC-specific detection. ${ }^{39-42}$ To sum up, it can be stated that a variety of epithelial-, mesenchymal-, and stem-cell markers can be applied for positive results in CTC-specific detection. Some examples of these key biomarkers are listed in Table 1. In addition, "negative markers" can be used for CTC detection in order to determine and eliminate debatable cells. These markers 
Table I Summary of key biomarkers used for CTC detection

\begin{tabular}{|l|l|l|l|}
\hline Epithelial markers & Mesenchymal markers & Stem-cell markers & $\begin{array}{l}\text { Lymphocyte, platelet, and } \\
\text { apoptosis markers }\end{array}$ \\
\hline EPCAM & N-cadherin & ALDHI & CD45 (lymphocytes) \\
\hline CK8, CKI8, CK19 & Cell-surface vimentin & CD44 & CD6I (megakaryocytes, platelets) \\
\hline E-cadherin & Twist I & Gangliosides (GD2, GD3, GD Ia) & M30 (apoptosis) \\
\hline ZOI & Akt and PI3K & ABC proteins & \\
\hline ESPRI & ZebI & & \\
\hline HER2 & $\begin{array}{l}\text { Alternative splicing proteins } \\
\text { (FGFR2IIlc, Mena, PI20 catenin) }\end{array}$ & & \\
\hline & Pls3 & & \\
\hline
\end{tabular}

Abbreviation: CTC, circulating tumor cell.

include, eg, white blood-cell marker CD45, platelet marker CD61, and apoptosis marker M30. ${ }^{39-42}$

\section{Detection and isolation methods with nanomaterials}

NMs can largely improve the efficiency and sensitivity of CTC enrichment, isolation, and detection. The unique properties of NMs can be used to accelerate detection and overcome some limitations in CTC detection. ${ }^{27}$ For safe application of $\mathrm{NMs}$ as a diagnostic device in cancer therapy, it is necessary to have a detailed understanding of interactions of NPs with cells, tissue, and organisms. ${ }^{43}$

\section{Nanoparticle-based CTC-detection and -isolation systems}

Extensive information about the behavioral and physicochemical properties of NMs that are engineered in technically stable environments, such as technical products, is needed to understand their changes in complex physiological or natural environments. ${ }^{1}$ Due to a high surface:volume ratio, NPs are quite likely to interact with (bio)molecules upon contact with biological and abiotic environments. This interaction leads to the formation of the so-called (bio) molecular corona. This (bio)molecular corona is formed spontaneously like an adsorption layer on the NP surface in complex biological environments, including simple and higher organisms. The interaction of NPs with organisms and control of their physiological responses are mediated by the adsorption layer, rather than the NP surface. Also, biomolecular adsorption can be affected by different properties of NPs, including shape, size, composition, surface charge, and surface functionalization. ${ }^{44-47}$

Protein absorption to NP surfaces was postulated in the pioneering work by Vroman, and thus is known as the "Vroman effect". ${ }^{8}$ This effect describes a dynamic change in protein-corona composition by adsorption and desorption. Consequently, in a complex biofluid like blood, which contains thousands of different proteins, abundant proteins are expected to desorb from the NP surface and be replaced by rare ones with higher affinity, leading to a relatively constant level of adsorbed proteins. ${ }^{47,49,50}$ The term "protein corona" was introduced to the NP community in 2007 by Cedervall et al. ${ }^{49}$ Subsequently, the loosely defined term "hard protein corona" was described as a strongly bound layer of biomolecules, representing an analytically approachable protein/biomolecule signature of NPs in a determined environment. ${ }^{1,44,50}$ Some models further indicate the presence of a "soft protein corona" around the "hard protein corona", consisting of loosely associated, rapidly exchanging, and highly complex biomolecule layers without direct contact with the NPs. ${ }^{1,44,49,51,52}$ Nevertheless, since it is determined that this "soft protein corona" (also called "soft corona cloud") desorbs during purification processes, its presence, analytical dissection, and important effects at the nano-bio interface are fully affirmed. These terms do not describe all types of coronas. Furthermore, unspecific ligand-receptor interactions have hardly been discussed in the context of biology or medicine, and no differences between "soft" and "hard" ligand-receptor interactions have been made. Current literature reveals that the term "soft" versus "hard" corona does not discriminate the corona types well enough to resolve the scientific questions. This is the reason it is recommended to term analytically approachable NP-protein complexes as "protein coronas". ${ }^{1}$

\section{Magnetic nanoparticles and nanoclusters}

One of the leading methods for CTC isolation is magnetic separation using magnetic NPs (MNPs; Figure 4). These MNPs bind to cells in vitro or in vivo and can be separated in the presence of an external magnetic field. Magnetic 


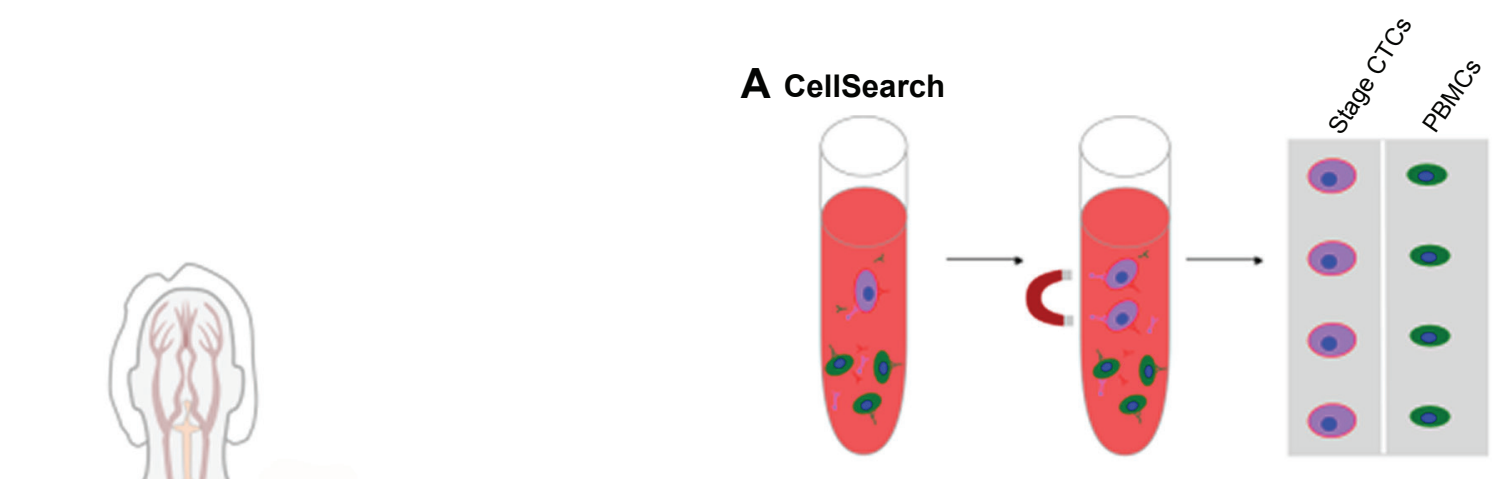

B AdnaTest
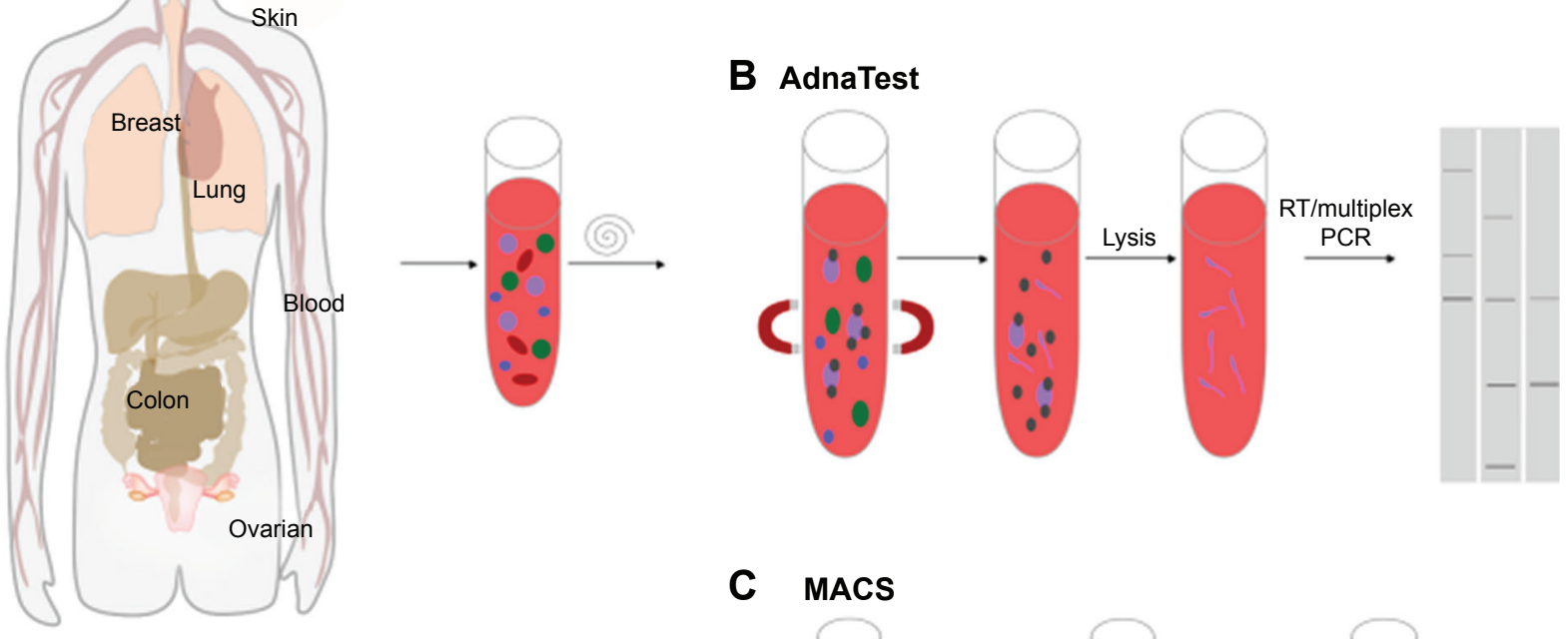

C MACS
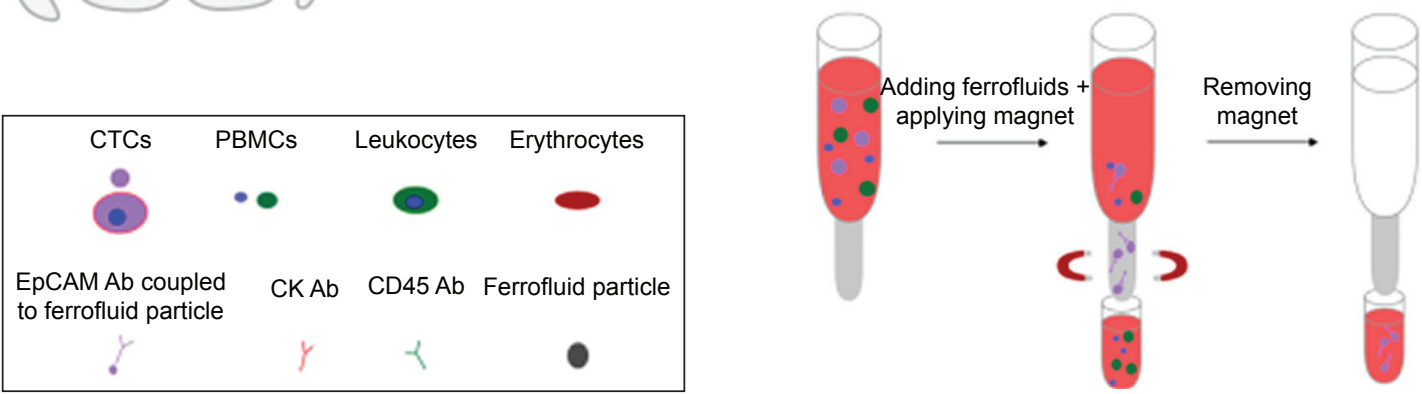

Figure 4 Illustration of methods for CTC isolation by magnetic separation using magnetic nanoparticles (NPs).

Notes: (A) The CellSearch system enriches CTCs using iron NPs linked with anti-EpCAM antibodies (Abs). Labeled cells are magnetically separated, and can be evaluated by immunofluorescence staining. (B) AdnaTest allows the immunomagnetic enrichment of CTCs via epithelial and tumor-specific antigens. After separation of potential CTCs from PBMCs, labeled cells are lysed, in order to analyze CTC gene expression via multiplex PCR. (C) Process of MACS using superparamagnetic Fe NPs within a magnetized steel-wool column.

Abbreviations: CTCs, circulating tumor cells; PBMCs, peripheral blood mononuclear cells; MACS, magnetically activated cell sorting; RT, real time.

NMs are related to dispersed MNPs or MNP clusters that are assembled in an organic or inorganic matrix.,.$^{20,21}$ The most commonly used MNPs include iron, cobalt, chromium, and their oxides exhibiting a magnetic moment after application of an external magnetic field. ${ }^{53}$ Iron oxide MNPs, such as magnetite $\left(\mathrm{Fe}_{3} \mathrm{O}_{4}\right) \mathrm{NPs}$, are chemically stable and biocompatible..$^{54}$ Depending on the particle shape and size, the magnetic response of iron oxide MNPs can be ferromagnetic or superparamagnetic. Whereas ferromagnetic NPs have remnant magnetization after removal of the external magnetic field, superparamagnetic NPs lack this characteristic, because of thermal fluctuations. ${ }^{20}$ Moreover, ferromagnetic NPs cannot be used for cell isolation, due to their poor stability, leading to aggregation in aqueous media. Consequently, only superparamagnetic NPs (SMNPs) or clusters thereof are suitable for cell isolation. SMNPs usually need suitable surface functionalization, because they also tend to get agglomerated in aqueous media. ${ }^{21,55}$ The surface of SMNPs is often modified by coating or grafting with surfactants, polymers, polyethylene glycol (PEG), polypeptides, or hydrophilic inorganic materials (silica and gold). ${ }^{21}$

Ding et al described an efficient magnetic capture and sensitive fluorescent labeling of CTCs based on near-infrared fluorescence $\mathrm{Ag}_{2} \mathrm{~S}$ nanodot-based signal amplification 
combing with immunomagnetic spheres. ${ }^{56}$ In addition, anti-EpCAM antibody labeling with magnetic nanospheres allows high capture efficiency of rare CTCs in wholeblood samples. ${ }^{56}$

Another method for CTC enrichment and isolation, so-called micro-nuclear magnetic resonance, allows fast and highly sensitive biomarker detection. Cells labeled with immunospecific SMNPs are detected with the help of magnetic resonance technology. The immunospecific SMNPs used are generally a few nanometers smaller than the beads, which are typically used for immunoseparation. The signal detection is based on magnetic interactions such that micro-nuclear magnetic resonance can be conducted with minimal sample-purification steps. This results in a simple assay procedure and reduced cell loss. ${ }^{57,58}$

The gold standard in CTC isolation is the US Food and Drug Administration (FDA)-approved CellSearch system, which enriches CTCs using 120-200 nm iron NPs (ferrofluid) linked with anti-EpCAM antibodies ${ }^{59}$ (Figure 4A). It is a fact that the magnetic force is proportional to the number of bound NPs. ${ }^{60}$ For this reason, cells bound to NPs are isolated more quickly than free NPs in a solution under the same external permanent magnet field, and thus cells can be selectively enriched. However, the CellSearch system is primarily designed for enumeration of CTCs with an epithelial origin expressing EpCAM and keratin. The workflow includes two instruments performing separate steps. While AutoPrep is executing CTC capture and immunostaining, the CellTracks analyzer evaluates the immunofluorescence-stained cells with semiautomated fluorescence microscopy. The specificity of sensitively captured and selected cells can be further increased by immunofluorescence staining with antikeratin and anti-CD45 antibodies. CD45-positive immunostaining determines captured cells as leukocytes..$^{53,61}$

On one hand, CellSearch represents a thorough, clinically validated method for CTC isolation, but on the other hand it has several limitations, due to its dependence on EpCAM expression. As such, only a very small proportion of CTCs in the blood sample of a patient can be detected in a limited interval. The process of EMT and accompanying downregulation of epithelial markers like EpCAM have already been discussed..$^{53}$

A comparable method for CTC isolation making use of magnetic enrichment is the AdnaTest (AdnaGen, Langenhagen, Germany). By using a mixture of magnetic microbeads, such as the superparamagnetic Dynabeads, AdnaTest allows the immunomagnetic enrichment of CTCs via epithelial and tumor-specific antigens (Figure 4B). Here, antibodies against EpCAM and tumor-associated antigens are simultaneously conjugated to magnetic beads for labeling of CTCs in peripheral blood. Afterward, labeled cells are lysed and mRNA extracted from captured cells and transcribed into cDNA. Subsequently, multiplex PCR is employed to analyze CTC gene expression. ${ }^{62,63}$ Compared to CellSearch, AdnaTest exhibits improved enrichment efficiency, due to the usage of two antibodies and the size of magnetic particles.

Another variation of the described magnetic isolation method is magnetically activated cell sorting (Miltenyi Biotec, Bergisch Gladbach, Germany). This differs from CellSearch and AdnaTest in using superparamagnetic $\mathrm{Fe}$ NPs combined with a magnetized steel-wool column. By removing the column from the external magnetic field, cells can be eluted from the column (Figure 4C). The advantage of this technique is the combined usage of magnetic beads coupled with various antibodies and the possibility to label cells with fluorescent antibodies. Thereby, it is possible to achieve direct enrichment and evaluation of captured cells without further detaching or staining procedures. ${ }^{64}$

All the aforementioned methods represent positive selection strategies for the specific isolation of CTCs from a bulk of other cells. The major limitation of positive CTC selection is that cells that do not express the targeted markers will not be captured. The use of negative-depletion strategies with magnetic beads is a possible solution to overcome this hurdle For negative depletion, a two-step procedure has been suggested comprising lysis of red blood cells and removing white blood cells by labeling with CD45-specific MNPs. Yang et al demonstrated that this method reduced the number of blood cells in a blood sample by two orders of magnitude.$^{65} \mathrm{In}$ fact, for blood samples spiked with cancer cells, a recovery rate of about $83 \%$ was accomplished. In summary, it remains a great challenge to capture CTCs efficiently, reduce the great number of normal blood cells in a sample, and protect rare CTCs from damage during lysis and different washing steps. ${ }^{21}$

\section{Gold nanoparticles}

Another extensively used NP type for improving the efficiency of CTC enrichment and capture is gold NPs (Au NPs) with enhanced light-absorption and -scattering properties. Binding between Au NPs and CTCs can be monitored quantitatively via photoacoustic signals or surface plasmon resonance (SPR) shifts. ${ }^{53,66,67}$ Researchers have synthesized a variety of different Au NPs, including gold nanospheres, nanorods, and nanoshells, that can be incorporated with targeting moieties, imaging or therapeutic agents, and other functionalities. ${ }^{53,68}$ 
Over the last two decades, the advances in synthetic techniques of NP production have enabled the preparation of $\mathrm{Au}$ NPs with a well-controlled size distribution from $2 \mathrm{~nm}$ to $>100 \mathrm{~nm}$. Au NPs display an SPR peak in the visible range of 510-550 nm, depending on particle size. An increase in particle size of Au NPs leads to a red shift in the SPR peak, and the width of the absorption band correlates closely with the size distribution of NPs. ${ }^{66,69}$ The SPR band of gold nanorods splits into two modes: one longitudinal at 520-550 nm and the other transverse vertical to the long axis at $720-750 \mathrm{~nm} .{ }^{53}$ Due to this unique SPR splitting, gold nanorods have been widely employed for CTC detection using techniques like photoacoustic imaging. ${ }^{70}$ The SPR peak of gold nanoshells can be tuned in the range from visible to the near-infrared region by changing the ratio of the core size to its shell thickness. Generally, they have an SPR band of $850-900 \mathrm{~nm} .{ }^{53,66}$

$\mathrm{Au}$ NPs can be utilized for in vivo imaging and ex vivo diagnostic sensors, due to their sensitivity, throughput, and flexibility. One example of in vivo application is CTC targeting by injection of Au NPs in the bloodstream. This allows real-time in situ monitoring of CTCs without blood sampling, sample preparation, or the following CTC-isolation steps. Furthermore, this application enables the phagocytic clearance of CTCs upon binding. ${ }^{21,53}$ The efficiency of these CTC-targeted Au NPs depends on their ability to overcome the high shear stress of blood circulation, escape the immunoresponse, and avoid unfavorable accumulation in organs. Due to the existence of target antigens/markers on normal cells, aspecific binding of NPs, and a high signal:background ratio, this method will produce some false-positive results. ${ }^{71}$ PEGylation of Au NPs is a commonly used strategy to overcome some of these issues, resulting in extended circulation time and decrease in aspecific binding. ${ }^{72,73}$

Photoacoustic imaging using Au NPs as contrast agent is an applicable in vivo technique for the detection of CTCs. This method utilizes acoustic waves generated by a laser, and detects acoustic vibrations resulting from the NP absorption of laser energy in blood vessels..$^{70,74,75}$ At SPR wavelength, Au NPs show a higher extinction coefficient compared to conventional organic dyes. Furthermore, the absorbed energy of $\mathrm{Au}$ NPs can be released rapidly by efficient heat conversion. Afterward, the efficient photothermal conversion can also be translated into highly efficient acoustic waves via the thermoelastic mechanism. ${ }^{75}$ In view of all these properties, this technique is quite suitable for monitoring physiological reactions of tumors, as well as enumeration and circulation of CTCs.

Zhang et al demonstrated research on spectra of blood cells, several tumor cells, immortalized cells, and clinical sample cells using silver film-substrate surface-enhanced Raman scattering (SERS) ${ }^{76}$ Raman spectroscopy is a commonly used unique vibrational spectroscopic technique that is able to measure inelastic light-scattering processes to provide fingerprint molecular identification information of cancer patients' blood cells and tissue. These cells display great differences in characteristic nucleic acid peaks. Clinical cancer-cell results display characteristic nucleic acid peaks with greater enhancement in comparison to red or white blood cells, which have almost none or only a slightly increased SERS signal. This study demonstrated a method for detection of CTCs with label-free SERS spectra by identifying blood cells and some kinds of tumor cells. These cells need a defined amount of DNA to be differentiated from white blood cells, which represents a disadvantage of this method. ${ }^{76}$

An ex vivo application of Au NPs for direct binding and separation of CTCs from patient blood is modification of $\mathrm{Au}$ NPs with CTC-specific ligands. ${ }^{77}$ This ex vivo CTC-detection method exhibits two advantages: first, it protects patients from the potential toxicity of labeled NMs for CTC capture, and second, it enables cultivation and analysis of the isolated cells. Au NPs can also be immobilized on a nanostructured surface (eg, an Au NP-modified chip) to allow binding of CTCs and label-free enumeration. Park et al described a strategy to isolate and release cancer cells from whole blood using a thiolated ligand-exchange reaction with Au NPs on a herringbone chip (NP-HBCTC chip). In comparison to antibodies coupled on flat silicon oxide surfaces, antibodycoated NPs that were chemically and directly assembled onto the HBCTC chip have several advantages: improvement of specific interaction of cancer cells with antibodies by increasing the available surface area, possibility for disruption of the metal-thiol interaction, resulting in the release of cancer cells from the surface, released cancer cells can be used for ex vivo cell culture and further molecular analysis, and the chemically self-assembled monolayers allow optimization of this method for application in complex surface topography without additional changes in the process..$^{21,78}$

\section{Fluorescence detection with quantum dots}

Besides enrichment and capture of CTCs, there are some methods specialized for the detection and analysis of these rare cells by cytometry or nucleic acid-based approaches. Cytometry allows an analysis of cells based on protein expression. Examples of this type of method are immunohistochemical staining, flow cytometry, and spectroscopic detection. The advantage of cytometry methods 
is the possibility to analyze detected cells further if cell lysis is not necessary for former procedures and to examine cell morphology if cells are reported microscopically. Nucleic acid-based methods assess tumor-specific genetic alterations by analyzing whole cells or extracted RNA or DNA by PCR, reverse-transcription PCR, and whole-genome amplification. Due to interference caused by the expression of normal cell markers, nucleic acid-based methods usually have low specificity, but high sensitivity. ${ }^{20,79}$

One of the leading techniques for CTC detection and analysis is the fluorescence-detection method. Organic dyes are usually used as imaging agents, although their use is limited by photobleaching (allows continuous dynamic imaging over minutes to hours), spectral overlap, low signal intensity, and the necessity of multiple light sources to excite different fluorophores in multiplex detection..$^{20,80}$

Quantum dots (QDs) are an example of NPs with inherent fluorescence that have been widely used for CTC detection with high quantum profit and tunable emission wavelengths. QDs display longer fluorescence lifetimes compared with organic fluorophores, which is important to enhance the sensitivity of surface marker-dependent CTC capture. ${ }^{54}$ Emission wavelengths of QDs can be tuned for a range of imaging applications, particularly in multicolor labeling, for simultaneous detection of multiple targets. QDs with different emission wavelengths but the same excitation wavelengths are applied for capture of heterogeneous CTCs. ${ }^{81}$ Additionally, QDs can be used for CTC detection through monitoring of extracted nucleic acids. Zhang et al developed a microfluidic beadbased nucleic acid sensor that depended on multienzyme-NP amplification and QD labeling. The simple concept of this sensor quantified targeted DNA by measuring fluorescencesignal intensity from QDs. ${ }^{82}$ Moreover, the solubility of QDs can be improved by surface functionalization with polymeric ligands or a layer of hydrophilic inorganic materials. Both QD functionalizations can be accomplished by ligand exchange or additional coating. ${ }^{83}$ Surface-functionalized QDs have been employed in various analysis methods, such as fluorescence resonance energy transfer-based cellular labeling ${ }^{84}$ and CTC detection. ${ }^{21}$ Due to their strong and stable fluorescence, QDbased ex vivo CTC detection is highly relevant for clinical applications. However, the use of QDs for in vivo CTC detection provokes heavy-metal toxicity. ${ }^{77}$

\section{Magnetic-optical bifunctional nanoparticles}

Magnetic-optical bifunctional NPs are composed of MNPs and optical components, such as fluorescence dyes, QDs, or
X-ray contrast agents. Fluorescent-magnetic bifunctional NPs have been used especially for multimodal imaging. It has been shown that fluorescent MNPs can be used for isolation and detection of multiple types of tumors simultaneously. ${ }^{53,85-87}$

Song et al demonstrated the targeting of leukemia Jurkat $\mathrm{T}$ cells and prostate LNCaP cells by labeling anti-CD3and anti-PSMA-conjugated MNPs with red- and yellowfluorescence dyes. ${ }^{87}$ The Jurkat and LNCaP cells were detected and distinguished using a magnet and fluorescence microscopy. This MNP-based system has the potential to be used as an ex vivo CTC-capture platform for CTC enrichment by exposure to magnetic force (eg, CellSearch). The combination of other materials with MNPs can lead to increased capture efficiency and more obvious CTC identification and differentiation using multimodal imaging. ${ }^{53}$

Kim et al developed a one-step detection method of CTCs in ovarian cancer by using a combination of silica $\left(\mathrm{SiO}_{2}\right)$ MNPs with incorporated organic dyes (rhodamine $\mathrm{B}$ isothiocyanate [RITC]) in the silica shell and conjugated cell surface-associated MUC1 on its surface. An MUC1positive human ovarian cancer cell line and a negative human embryonic kidney cell line were used to study the specific targeting efficiency of $\mathrm{MUC1}-\mathrm{SiO}_{2}$ MNPs (RITC). Based on flow cytometry, this detection technology was capable of detecting 100 cells of ovarian cancer origin in $50 \mu \mathrm{L}$ whole blood. ${ }^{88}$ Fluorescent $\mathrm{SiO}_{2}$ NPs can also be conjugated to an aptamer for CTC detection. One detection method of leukemia cells using aptamer-modified fluorescent $\mathrm{SiO}_{2}$ NPs was presented by Tan et al. ${ }^{89}$ Due to selection of specific aptamers, this method could be adaptable to other types of cancer. Additionally, aptamer-NP conjugation can be advanced for drug-delivery applications. ${ }^{89}$

\section{Graphene and graphene oxides}

Graphene is an atomically thick, two-dimensional sheet of $\mathrm{sp}^{2}$-hybridized carbon that is ordered in a honeycomb structure. Additionally, it is the basic building block for graphitic materials of other dimensionalities, such as graphite and carbon nanotubes (CNTs). Graphene has specific chemical and physical properties, such as high surface area, good mechanical strength, high intrinsic mobility, and great thermal conductivity with optical transmittance and electrical conductivity. ${ }^{53,90,91}$ Charge transfer between adsorbed molecules and graphene induces their chemical response. Due to the excellent electromagnetic detection of small biomolecules, graphene and graphene oxide (GO) have been applied for electrical CTC detection. ${ }^{92} \mathrm{GO}$ can be 
functionalized through PEG-based chemistry, and GO size is controllable by sonication time and filtration..$^{93,94}$ Moreover, one of the most important properties of GO for biological and medical research is improvement in imaging by taking advantage of optical transparency. ${ }^{95}$

Wu et al presented $\mathrm{GO}$ as a starting point for the electrical capture, detection, and fluorescence imaging of CTCs. ${ }^{96}$ After treatment of a glassy carbon electrode with chitosan, GO was deposited and reduced. Anti-EpCAM was conjugated to the surface by a cross-linker glutaraldehyde for cell capture. The combination of anti-EpCAM and a marker for hepatocellular carcinoma, anti-GPC3, was conjugated to $\mathrm{SiO}_{2} \mathrm{NPs}$ modified with $\mathrm{ZnSe}$ and incubated with the captured cells. Enumeration of captured cells was performed by square-wave voltammetry measurements, as well as fluorescence imaging. For proof of principle, cells were detected at concentrations as low as five cells/mL using spiked hepatocellular carcinoma cells. Further experiments with spiked cells in blood and clinical samples were not performed.

Furthermore, a novel biosensor with GO NPs for detection of breast cancer biomarkers was developed by Myung et al. ${ }^{97}$ As shown by transmission electron microscopy, amine-terminated $\mathrm{SiO}_{2}$ NPs were coated with negatively charged GO. These GO-coated NPs were self-organized on the surface of functionalized oxide substrate with a metal electrode. Reduction of GO to graphene induced electrical conductivity enabling the detection of HER2, a marker for breast cancer, by measuring the relative conductance change.

Further research by Yoon et al led to the application of GO chips for sensitive CTC capture. ${ }^{92} \mathrm{GO}$ nanosheets were self-assembled on a gold-patterned silicon surface via a positively charged intercalating agent and functionalized with PEG. ${ }^{98}$ Anti-EpCAM antibody was used to functionalize the substrate by utilizing cross-linker and biotin-avidin linker chemistry. Different cancer cell lines (MCF7, Hs578T, PC3) were spiked into buffer or blood and flowed through the GO chip. Subsequently, captured cells were cultivated on the gold-patterned surface with GO sheets, which was highly beneficial, due to the virtually two-dimensional capture surface. Blood samples from patients with breast, pancreatic, and early lung cancer were processed using these devices with a capture result of two to $23 \mathrm{CTCs} / \mathrm{mL}$. The cultivation of captured CTCs opens the possibility for further applications and analysis. ${ }^{92}$

Tian et al developed an ultrasensitive electrochemical detection method based on a composition of reduced $\mathrm{GO}-\mathrm{Au}$ NPs as a support material with copper(II) oxide $(\mathrm{CuO})$ nanozymes. ${ }^{99} \mathrm{CTC}$ of a breast cancer cell line (MCF7) were detected by recognition between MUC1 on the cancer-cell membrane and MUC1 aptamer on an electrochemical cytosensor. $\mathrm{CuO}$ nanozymes functioned as a catalyst and were used as a signal-amplifying nanoprobe. Due to the specific composition of MUC1 and MUC1 aptamer, the cytosensor detected CTCs easily in a wide range of 50-7,000 cells $/ \mathrm{mL}$ with a very low detection limit. ${ }^{99}$

\section{Dual enrichment and detection}

As mentioned, the efficiency of CTC capture can be effectively improved by using combinations of isolation materials or conjugated multiple antibodies. The exact analysis of in situ expression of different surface biomarkers may be limited by using multiple antibodies for CTC capture, because a lot of biomarkers used for CTC capture are also important for CTC characterization. For each cancer subtype, only a limited number of surface proteins applicable as biomarkers are known. Additionally, the extremely rare nature of CTCs is another limitation factor.

Lee et al developed hybrid NPs to offer the possibility to perform in situ expression analysis and positive selection of biomarker-expressing cells by targeting the same marker using a single compound. ${ }^{100}$ The hybrid NPs consisted of three parts: antibodies that bound to specific proteins on CTCs, QDs that emitted fluorescence signals, and biotinylated DNA, which allowed capture of the CTC-hybrid NP complex to a chip. The DNA linker was cleaved off by restriction enzymes after cell capture to recover CTCs from the chip. ${ }^{100,101}$

In this study, the authors used three breast cancer cell lines (MCF7, SKBR3, and MDA-MB-231) for the evaluation of hybrid NPs. Each hybrid NP exhibited an exposed biotin arm binding to streptavidin-coated pillars in the “capture-and-recovery chip". Thereby, capture efficiency depended on the density of biotin in hybrid NP-bound cells. To determine capture efficiency, breast cancer cells were spiked into blood samples that were incubated with hybrid NPs. Afterward, the cell suspension was flowed through the capture-and-recovery chip, and captured cells were screened based on cell morphology and immunofluorescence staining. Captured cells were released from the chip by treatment with restriction enzymes and transported to the recovery chamber by microfluidic flow. To increase CTC-capture efficiency, different antibodies - EpCAM, EGFR, and HER2 - were used simultaneously. This allowed the isolation of CTCs that had undergone EMT and thus lacked or only weakly expressed EpCAM. With three different hybrid NPs, one for each of three proteins, CTC-capture efficiency of about $88 \%$ 
was achieved. This result included about $90 \%$ of isolated breast cancer cells (MDA-MB-231), which are EpCAMnegative cells, that were captured. Additionally, the captured cells were simultaneously identified by their in situ protein expression, with an identification accuracy of about $92 \%$. To sum up, this method succeeded in simultaneous capture, enumeration, and identification of CTCs based on in situ protein expression. ${ }^{100}$

\section{Carbon nanotubes}

CNTs have been used in advanced research applications because of their remarkable electrical, mechanical, and physicochemical properties. CNTs are graphitic hollow filaments of alterable lengths that can reach several hundred micrometers. Two types of CNT are known: single-walled (SWCNTs) and multiwalled (MWCNTs). SWCNTs comprise a single cylindrical sheet of graphene, and MWCNTs comprise several concentric, coaxial, rolled-up graphene sheets. The size of CNTs differs, with a diameter typically ranging $0.4-3 \mathrm{~nm}$ for SWCNTs and 2-200 nm for MWCNTs. ${ }^{102}$ CNTs also include carbon nanofibers, which defend a less perfect graphenesheet arrangement featuring layers of graphene nanocones. These nanocones are also called "cups" and usually denote stacked-cup CNTs, which consist of strong flexible filaments of 70-200 $\mathrm{nm}$ in diameter and $10-100 \mu \mathrm{m}$ in length. ${ }^{103}$ Chemical vapor deposition is the most used method for CNT synthesis. ${ }^{102,104}$ CNTs behave as a metal or semiconductor, depending on their diameter and helicity. Possible variants of the conductance of CNTs can be induced by mechanical deformations or chemical binding, which can be detected by electron-current signals. All properties of CNTs mentioned make them suitable chemical and biological sensors. ${ }^{20}$

Shao et al developed an application of CNTs for electric detection of cancer cells in blood with an SWCNT field-effect transistor array device. ${ }^{105}$ This device comprised 20 pairs of electrodes with a single CNT between each pair. Additionally, the CNTs were functionalized with antibodies to recognize breast cancer cells. The binding of cancer cells to the CNTs resulted in a $60 \%$ decrease in conductivity. This assay contains a sensing area that was able to detect potential CTCs with low protein expression. Another advantage of this system is that enrichment steps are no longer needed, with the result that cancer cells can be directly tested. Nevertheless, this assay also has some challenges, like a very small volume of analyzed patient blood $(<10 \mu \mathrm{L})$, bearing the risk of missing CTCs. There is also the possibility of CTCcounting difficulties, because the signal is determined by a single cell reaching the space between the electrodes.
Another example of using the electrical properties of CNTs for detection of CTCs from whole-blood samples was demonstrated in a recent study by Liu et al. ${ }^{106}$ The researchers developed a sensitive CNT-based biosensor for direct detection of CTCs in whole blood using the good conductivity of MWCNTs. This biosensing method is based on binding of anti-EpCAM antibodies to cancer cells, resulting in increased electron-transfer resistance. The detection of cells was limited to five cells per $\mathrm{mL}$ of blood, and an electrical response was observed that was proportional to the concentration of liver cancer cells. ${ }^{54,106}$

\section{Microfabricated filters}

Since the majority of blood cells are smaller than CTCs, membrane-microfilter devices are a suitable tool for separation of CTCs from whole-blood samples by cell-size exclusion. ${ }^{12,42,107,108}$ Whereas CTCs can vary in size and shape, typical dimensions of blood cells are 5-9 $\mu \mathrm{m}$ for erythrocytes, 10-15 $\mu \mathrm{m}$ for granulocytes, $7-18 \mu \mathrm{m}$ for lymphocytes, and 12-20 $\mu \mathrm{m}$ for monocytes. ${ }^{108}$ The size-exclusion approach makes use of a parylene-based membrane-microfilter device comprised two parylene-membrane layers and a photolithography-defined gap to minimize stress. Cells isolated with this microfilter device are viable and can be used for further molecular analysis. ${ }^{107,108}$

Zheng et al developed a parylene-based membranemicrofilter device with integrated electrodes containing $11 \mu \mathrm{m}$-diameter circular pores. ${ }^{108}$ The smallest distance between the pair of electrodes for each pore was $8 \mu \mathrm{m}$. For the experiments, a defined number of LNCaP cells (metastatic prostatic adenocarcinoma cells) were stained with hematoxylin and spiked into blood samples. This cell suspension was loaded into a syringe and dispensed to pass through the filter. The flow through was collected by the bottom syringe. Immunostaining was used to distinguish potential CTCs from other cells on the filter. The recovery rate of the membrane filters was evaluated by hemocytometry using the hematoxylin staining of LNCaP cells. To sum up, the filter design resulted in $89.0 \% \pm 9.5 \%$ recovery from blood. The advantage of this technology is the possibility of label-free isolation of CTCs and sensitivity to cell-size in a blood sample. However, the size and shape of CTCs is rather heterogeneous, leading to the risk of losing CTCs that are smaller than the filter pores. ${ }^{42}$

\section{Microfluidics and "lab-on-a-chip" technology}

In comparison to conventional methods, microfluidic lab-ona-chip devices provide unique platforms to perform isolation 


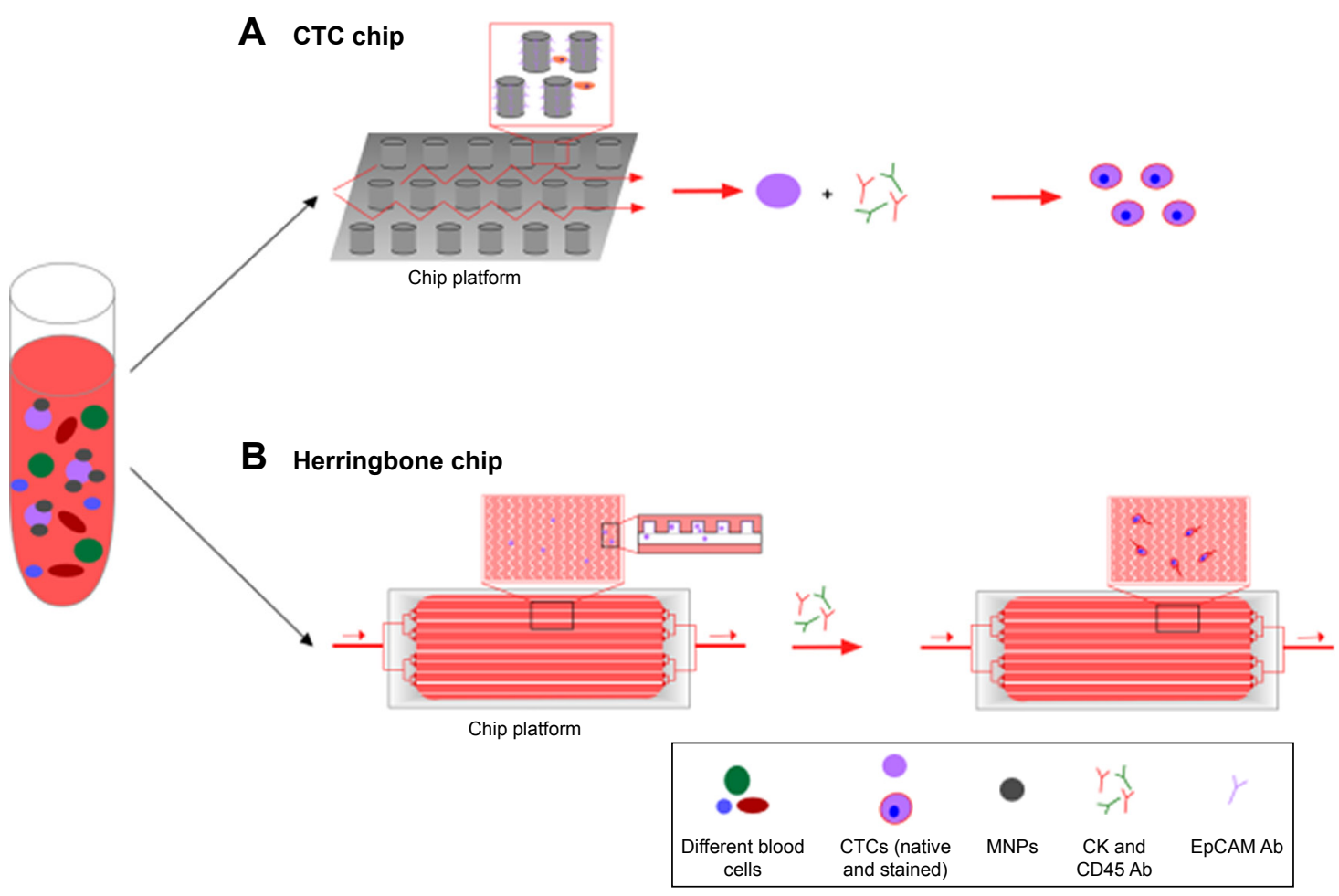

Figure 5 Microfluidic chip design of CTC chip (A) and herringbone chip (B).

Notes: Whole-blood sample is pushed through the surface of the chip, which is coated with a CTC-specific antibody, such as EpCAM. Chips differ in their architecture, containing either Ab-coated microposts (A) or herringbone-etched microchannels (B). Captured cells are stained for CK, CD45, and DAPI. Identified CTCs can be enumerated. Abbreviations: CTC, circulating tumor cell; Ab, antibody; MNPs, magnetic nanoparticles.

and analysis of CTCs with only one chip, avoiding the imminent loss of these rare cells during the experimental steps of sorting, enumeration, and analysis. ${ }^{126}$ This technology has become mainstream in CTC enrichment and detection, due to its cost-effectiveness, miniaturization, and improvement in efficiency, since it can be integrated into other techniques. ${ }^{13,127}$ The development of the majority of current microchip platforms is based on magnetic force, affinity, size, or other physical properties. ${ }^{128}$ Two types of microfluidic devices are used for CTC detection: the immunomagnetic-based method for CTC detection (eg, CTC chip), and antibody labeling combined with physical isolation (Figure 5), which can consist of different materials like silicon, glass, or thermopolymer.

An example of microfluidic applications for CTC detection was presented by Ortega et al and based on a microfluidic immunosensor with synthesized silver NPs covered by chitosan. ${ }^{129}$ Integrated silver NPs-chitosan in the microfluidic immunosensor were functionalized with anti-EpCAM antibodies to capture EpCAM biomarkers in peripheral blood samples. Subsequently, bound EpCAM biomarker was recognized by HRP enzyme-labeled secondary antibodies that reacted with its enzymatic substrate. This enzymatic process generated a product through oxidation on the electrode surface, which resulted in a current magnitude proportional to the level of EpCAM. This microfluidic immunosensor method presents a low-cost and simple application for detection and reliable prognosis of epithelial-origin tumors in biological samples. ${ }^{129}$

\section{Immunomagnetic-based CTC chips}

The opportunity to perform immunomagnetic separation on a microfluidic device that combines the advantages of two techniques, immunomagnetic separation and the microfluidic device, resulted in a new developmental stage in immunomagnetic separation. The capture efficiency depends on the magnetic strength and drag force under the flow condition. Cells bound to large numbers of NPs can be captured more efficiently by using both forces. ${ }^{20}$ Typically, the cell isolation in microfluidic channels is performed in the presence of a permanent magnet located under the bottom of the chip. ${ }^{91,130}$ It has been shown that $>85 \%$ of cancer cells spiked in blood can be recovered by EpCAM antibody-functionalized $\mathrm{Fe}_{3} \mathrm{O}_{4}$ NPs at a speed of $10 \mathrm{~mL} / \mathrm{h}$ using NdFeB block magnets. ${ }^{20,130}$ Separation efficiency can be improved by inverting the microchannel so that the magnet is placed on top of the 
channel, which results in gravity direction opposite to the magnetic field. ${ }^{131}$

Miniaturized microfluidic technology, called micro-Hall detection, allows fast screening of CTCs in a blood sample. Using this system, MNP-immunolabeled cells can be detected via monitoring the magnetic moments of cells in flow on a single microfluidic chip. Micro-Hall detection can selectively and sensitively detect a wide range of cellular biomarkers and can be employed for screening of multiple biomarkers on individual cells. A panel of MNPs with different magnetization properties can be utilized to label different cellular markers. By using the particles' classifiable magnetization properties, the quantity of each MNP type representing the expression level of a distinct target biomarker in a single cell can be obtained. ${ }^{125}$

\section{Silicon-based CTC chips}

Nagrath et al described a microfluidic device called a CTC chip, which is able to isolate CTCs efficiently and reproducibly from the blood of patients with common epithelial tumors. ${ }^{132}$ This microfluidic system is composed of a CTC chip etched in silicon, a manifold to enclose the chip, and a pump producing the flow through the capture module (Figure 5A). The CTC chip contains an array of microposts that are chemically functionalized with EpCAM antibodies. There are two essential parameters that influence cell-capture efficiency: flow speed and shear force. Flow speed is important, due to its influence on the duration of cell-micropost contact, whereas shear force has to be minimized to guarantee a high cell-micropost attachment. The chip is very small (about $25 \times 66 \mathrm{~mm}$ ) and contains repeated patterns of equilateral triangular arrays to maximize the interactive surface for cell-micropost contact. In total, this array integrates about 78,000 microposts within a surface area of $970 \mathrm{~mm}^{2}{ }^{132}$

\section{Glass/PDMS-based CTC chips}

After the development of the CTC chip, Stott et al reported a modified herringbone CTC-capture chip $^{133}$ (Figure 5B). This technique increases the interaction of flowing cells and anti-EpCAM-functionalized polydimethylsiloxane (PDMS) microchannels through passive mixing. PDMS, also called dimethicone, is a polymer that can be used for microfluidic chips. To disrupt streamlines and increase capture efficiency, microvortices were created and integrated with the herringbone-chip through chevron patterns on a PDMS ceiling. Due to the antibody-antigen interaction, cells tether to the chip and can be stained afterward. The transparency of these glass chips also allows clear imaging using different types of light microscopy-based techniques. ${ }^{91}$
Shi et al engineered nanotopograhy of various dimensions and geometry on an elastomeric PDMS substrate to capture CTCs. It was suggested that cell adhesion using nanotopography could be a valuable application to isolate CTC antibody- and size-based independence. Cancer cell lines of different types, metastatic status, and surface-marker expression were used to analyze the capture performance, with efficiency up to $52 \%$. As mentioned by Shi et al, the influence of nanotopography was less significant. However, this study contains useful information on nanotopography optimization for further improvement of CTC-capture efficiency. ${ }^{134}$

\section{Thermopolymer-based CTC chips}

As an alternative to silicone, polymethylmethacrylate (PMMA) is also used as a substrate for microfluidic CTC capture and analysis, with the advantages of low cost and magnificent optical transparency. PMMA is suitable for fabrication techniques, such as injection molding and hot embossing. On the surface of PMMA, carboxylic acid groups can be generated by ultraviolet exposure to explore the concentration of proteins, electroless deposition, and cancer-cell capture. ${ }^{135}$ The roughness of the surface area can be increased by high-intensity light, due to the enhanced surface area for functionalization. Furthermore, at low temperatures, the thermal bonding passes through to preserve these microfeatures. ${ }^{136}$ Consequently, a high-throughput microsampling unit functionalized with anti-EpCAM antibodies was developed for capture and enumeration of CTCs with an included conductivity sensor. ${ }^{91}$

\section{In vivo enrichment and detection with nanomaterials}

Due to the limitation of blood-sample volume that can be obtained from patients and also handled by detection systems, ex vivo CTC-isolation techniques show relatively low sensitivity. To overcome these limitations, Saucedo-Zena et al developed a medical device for screening large blood volume in vivo. This device allows the capture of CTCs directly from the circulating bloodstream of patients. During incubation in the vein, the device is exposed to nearly $1 \mathrm{~L}$ of blood, leading to an enormous increase in capture efficiency. Based on the Seldinger technique, ${ }^{137}$ this device is composed of a structured and functionalized structured medical wire (FSMW). The usage of FSMW for capturing rare cells is similar to ex vivo CTC-detection technologies, and requires CTC-specific antibodies like epithelial cell markers and/or cytokeratin. ${ }^{138,139}$

The FSMW is composed of a stainless-steel medical wire of $0.5 \mathrm{~mm}$ diameter and $160 \mathrm{~mm}$ length. The tip of the wire 
is functionalized and covered with a $2 \mu \mathrm{m}$-thick gold layer, which is fixed on the device by galvanization and covered by a 1-5 $\mu \mathrm{m}$ linear synthetic polycarboxylate layer. The hydrogel is covalently coupled with antibodies against the EpCAM protein, and can be stored in distilled water at $4^{\circ} \mathrm{C}$ until use. ${ }^{138-141}$

Before use of the device, a $20 \mathrm{G}$ peripheral venous catheter has to be placed into the cubital vein of a patient to enable the insertion of the FSMW through the catheter. After incubation for 30 minutes, the FSMW is removed from the vein, and bound cells can be recovered via washing. Captured CTCs are characterized by immunocytochemical staining for cytokeratin or EpCAM. The results include the identification via staining and enumeration of the captured cells. ${ }^{138,140}$

\section{CTC-targeted nanomedicine}

There is still no FDA-approved antimetastatic agent that can directly target tumor metastasis. ${ }^{21}$ Given the pivotal role of CTCs in tumor metastasis, therapeutic targeting and specific depletion or destruction of CTCs from blood vessels may be an intriguing strategy for prevention of tumor metastasis. With the rapid development of nanoscale-material science and the wide application of nanobiotechnology in the biomedical field, researchers have designed and developed a variety of nanosystems for targeted delivery of therapeutic agents to CTCs to destroy them efficiently and thereby inhibit tumor metastasis.

\section{DNA-based nanodevices}

Nanosystems fabricated by DNA have been extensively employed for various biomedical applications, due to their excellent biocompatibility, accurate interactions among base pairs, programmability, and automated synthesis. ${ }^{142,143}$ Wang et al developed a novel structure-switching aptamer for CTC-triggered photosensitizer (PS) release and specific CTC inhibition. ${ }^{144}$ This nanosystem is composed of a PDMS-glass supporter and a PS-labeled hairpin switch aptamer (HAS) immobilized on the supporter. The presence of CTCs can induce the formation of a HAS structure, due to the specific interaction between the aptamer and CTCs leading to the detachment of the PS-labeled aptamer from the supporter. The PS-labeled aptamer is activated by light and produces singlet oxygen $\left({ }^{1} \mathrm{O}_{2}\right)$ when flowing through blood vessels, resulting in the specific killing of CTCs. Subsequently, the authors established a "sense-and-treat" DNA nanostructure immobilized on a supporter, which consisted of a HAS and a DNA tetrahedron (Figure 6) ${ }^{142}$ Doxorubicin (Dox) and a PS were coencapsulated into the DNA-tetrahedron structure, due to the latter's ability to enhance cellular internalization of anticancer agents and increase drug-loading content. The nanodevice can sense the existence of CTCs and interact with them, leading to the release of Dox and PS by the DNA tetrahedron. PS is activated after irradiation by an integrated household LED and generate toxic ${ }^{1} \mathrm{O}_{2}$, resulting in synergetic destruction of CTCs with Dox. This localized drug-delivery nanosystem combines chemotherapy and photodynamic therapy, and enables the specific destruction of CTCs without affecting normal cells. We have reason to believe that more DNA-based nanoscale drug-delivery systems based on the sense-and-treat strategy with higher CTC-destruction capability will be designed and developed in the future.

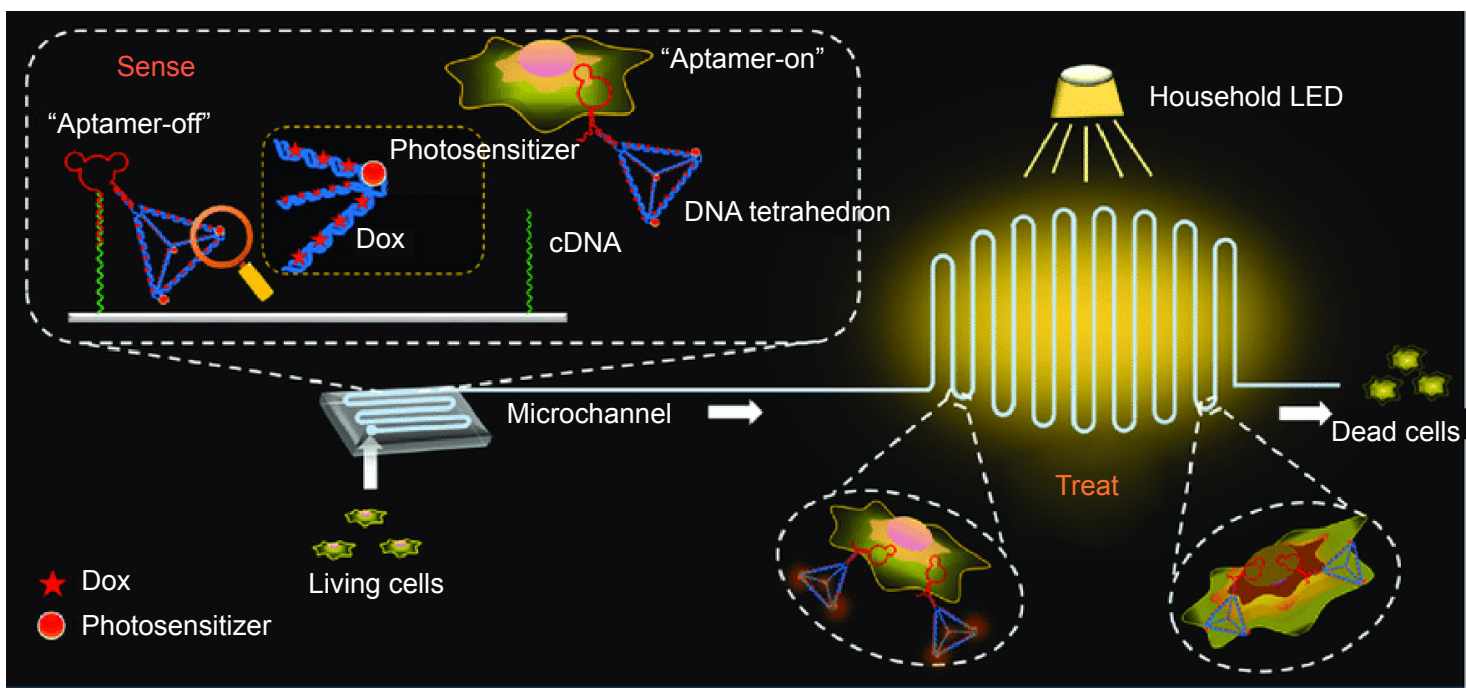

Figure 6 Synergetic detection and destruction of CTCs by a "sense-and-treat" DNA nanosystem.

Notes: Reproduced with permission from Chen N, Qin S, Yang X, Wang Q, Huang J, Wang K. "Sense-and-treat" DNA nanodevice for synergetic destruction of circulating tumor cells. ACS Appl Mater Interfaces. 2016;8(40):26552-26558. Copyright @ 2016 American Chemical Society. ${ }^{142}$

Abbreviations: CTCs, circulating tumor cells; Dox, doxorubicin. 


\section{Dendrimers}

Dendrimers are particularly suitable for antitumor-agent delivery, due to their high solubility, uniform size and composition, and ease of functionalization because of a high number of surface functional groups. ${ }^{145}$ Xie et al reported a novel polyamidoamine dendrimer-based nanoplatform for capturing CTCs in blood vessels and disturbing their adhesion to the vascular endothelial layer to form new micrometastatic foci. ${ }^{146-149}$ The surface-functionalized nanoscale dendrimers were coated with two antibodies (anti-EpCAM and -sLeX) to target surface biomarkers of human colorectal CTCs. Whereas it has been reported, that targeting of EpCAM can directly disturb the adhesion process of CTCs, the sLeX (sialyl Lewis X) antibody can indirectly interrupt the adhesion between CTCs and endothelial cells via sLeXE-selectin (ES) interaction. ${ }^{146}$ In comparison to their single antibody-coated counterparts, dual-antibody conjugates displayed remarkably enhanced efficiency and specificity in recognizing and capturing CTCs from a large population of leukocytes or red blood cells in vitro, as well as from the blood of patients and mice in vivo. Flow cytometry analysis demonstrated that the inhibitory effect of the dual-antibody conjugates on CTCs was attributed to dose-dependent S-phase arrest. Recently, this group developed dual aptamer rings conjugated on dendrimers and thus were able to simultaneously target EpCAM and Her2 biomarkers on CTCs in the presence of millions of normal cells with excellent stability and accuracy. ${ }^{150}$ This study provides new ideas for the design of more powerful and intelligent nanomedicines allowing the prevention of tumor metastasis via suppressing CTCs and blocking their adhesion to blood vessels. Zheng et al presented a type of barcode particle consisted of spherical colloidal crystal clusters that are surrounded with dendrimer-amplified aptamer probes. ${ }^{151}$ A specific aptamer functionalization allows the particles to interact with specific CTC types, and the dendrimers used are able to amplify the effect of the aptamers. Particles with these capabilities are able to capture, detect, and release multiple types of CTCs from clinical samples. ${ }^{151}$

\section{Mesoporous silica nanoparticles}

During the past few years, mesoporous silica NPs (MSNs) with pore size of 2-50 $\mathrm{nm}$ have drawn considerable attention, especially for drug-delivery applications, due to their attractive properties, such as large surface area, mesoporous structure, controllable pore size, ease of surface functionalization, and good biocompatibility. ${ }^{152} \mathrm{Jia}$ et al constructed an MSN-based nanoplatform incorporated with the abortifacient mifepristone (MIF) and functionalized with EpCAM antibody. ${ }^{153}$ This combination can specifically recognize colorectal cancer cells in vitro through EpCAM targeting, and its high biostability enables effective MIF delivery, leading to lung-metastasis inhibition in mice. Jia et al also developed novel MSN-based nanomissiles that were synthesized by encapsulating Dox into MSN pores and covalently linking EpCAM and CD44 aptamers on the surface. ${ }^{154}$ These nanomissiles can selectively and efficiently deliver Dox into CTCs and deactivate them, thereby preventing metastasis formation in vivo through the synergistic effects of Dox, EpCAM-antibody DNA aptamer, and CD44-antibody DNA aptamer by repressing cell proliferation and inhibiting cell migration. These studies expand the application of MSNs as nanoscale delivery systems from tumor-growth retardation to tumor-metastasis suppression.

\section{Liposomes}

Over the last five decades of research, liposomes have shown their solid benefits as most common and well-investigated nanocarrier for clinical applications in medical industry. Liposomes are responsible for delivery of several smallmolecule drugs. ${ }^{155}$ Liposomes are biomimetic NPs that are formed from a self-assembling concentric lipid bilayer and envelop an aqueous core domain. ${ }^{156}$ Due to their amphiphilic nature, phospholipids arrange in polar shells in aqueous solutions. This is a thermodynamically favorable organization, further elevated by hydrogen bonding, van der Waals forces, and electrostatic interactions. ${ }^{155-158}$ Due to the aqueous core and lipid bilayer, liposomes are able to encapsulate hydrophilic and lipophilic molecules. There are many advantages of using liposomes in a wide range of medical applications, including their biocompatibility, atoxicity, and biodegradability. Because of the improved drug pharmacodynamics and pharmacokinetics, as well as the controllable release behavior of the loaded drugs, liposomes are used preferably in drug delivery. Rapid clearance of liposomes out of the blood by macrophages from the reticuloendothelial system can be prevented by coating the liposome surface with PEG. ${ }^{156,159}$ Subsequently, it is possible to conjugate the liposome surface with targeting molecules mediating active accumulation of liposomes in cancerous tissue. Liposomes can be loaded with NPs functioning as imaging agents, such as MNPs, QDs, and Au NPs. These NPs can be incorporated into the liposomal structure inside the aqueous core or within the lipid-bilayer membrane. Moreover, liposomes can also be functionalized by NPs conjugated on their theranostic surface. For example, liposomes containing iron oxide 
NPs are usually used as theranostic agents for magnetic resonance-imaging applications. Liposomes with entrapped magnetic iron oxide NPs exhibit advantageous characteristics, such as reduced phagocytic elimination (opsonization) and aggregation. In addition, encapsulation of iron oxide NPs in liposomes improves their dispersibility and increases blood-circulation time. Again, these liposomes can be further functionalized with targeting ligands for specific delivery to disease sites. $^{21,156}$

Mitchell et al synthesized a CTC-targeted Dox-delivery system by modifying liposomal Dox (L-Dox) with ES and PEG. ${ }^{160,161}$ ES can recognize and bind with the sialylated carbohydrate ligands overexpressed on the surface of CTCs. ES-PEG L-Dox can specifically target, capture, and kill CTCs in both static and dynamic environments, without affecting red blood cells or leukocytes. By immobilizing ESPEG L-Dox onto halloysite NT (HNT)-coated microtubes, obviously improved CTC-capturing and -killing ability was observed. It is noteworthy that HNT-liposome surfaces can enhance chemotherapeutic delivery to CTCs and thus greatly reduce the possibility of tumor metastasis. Moreover, this unique surface can significantly reduce undesired side effects to normal cells and the dosage needed for CTCtargeted chemotherapy. This work opens up new avenues for development of other powerful strategies for effective delivery of chemotherapeutics to CTCs.

\section{Polymeric micelles}

Polymer-based NPs represent polymeric colloidal particles in a size range of several nanometers allowing encapsulation, adsorption, or conjugation of therapeutic agents within their polymeric matrix or their surface. ${ }^{162,163}$ Due to their properties of biodegradability and biocompatibility, as well as the possibility of controlling their chemical and physical properties by molecular synthesis, polymeric materials are an important cancer drug-delivery system. Polymers can be linear, globular, or branched, and may differ in size. ${ }^{164-166}$ Linear amphiphilic block copolymers form core-shell particles, the so-called micelles. These micelles are composed of a hydrophobic core to minimize aqueous exposure and a hydrophilic shell to stabilize the core, built up in an aqueous ambience. ${ }^{167}$ These properties not only allow loading of hydrophobic small-molecule drugs in the core but also provide steric protection of the shell. Additionally, hydrophilic drugs, including macromolecules like nucleic acids, can be incorporated into polymeric NPs by electrostatic attraction or chemical conjugation. Langer and Folkman demonstrated for the first time the feasibility of controlled release of macromolecules via polymers, clearing the way for the development of antiangiogenic drug-delivery systems and pioneering novel areas for the delivery of macromolecules. ${ }^{168,169}$

During the development of different drug-loaded devices, a number of materials have been used like polyamides, poly(amino acids), polyesters, and polyacrylamides with thermoplastic aliphatic polyesters such as poly(glycolic acid), polylactic acid (PLA), and copolymer poly(lactic $c o$-glycolic acid). ${ }^{170-173}$ The latter is one of the most successfully used biodegradable polymers for biomedical applications, because its hydrolysis leads to metabolite monomers, lactic acid, and glycolic acid. ${ }^{169,174}$ PLA- and chitosan-based polymers have also been used for the development of polymeric micelles. Furthermore, PLA shows low toxicity with an additional slightly negative surface charge, ${ }^{175}$ and chitosan, a polysaccharide, is widely used as a carrier of hydrophilic drugs. Aspecific side effects of the antitumor agent Dox can be reduced by Dox encapsulation in chitosan NPs tested for the treatment of solid tumors in vivo. ${ }^{176,177}$

Deng et al demonstrated the use of a Dox-loaded biodegradable polymeric micelles for killing of CTCs and finally suppressing tumor metastasis. ${ }^{121}$ In this study, the authors synthesized monomethyl PEG-poly( $\varepsilon$-caprolactone) diblock copolymers for the preparation of Dox-loaded micelles via pH-induced self-assembly. Whereas unloaded micelles exhibited minimal cytotoxicity to $4 \mathrm{~T} 1$ cells, even at very high concentrations, the functionalization of micelles loaded with Dox induced slightly higher cytotoxicity compared to free Dox. Dox micelles were able to inhibit tumor growth, suppress tumor metastasis by killing CTCs, and extend the survival rate in transgenic zebrafish. The improved activity against tumors and metastasis was also demonstrated in a mouse model. Furthermore, Dox micelles induced apoptosis and reduced the number of proliferation-positive cells in tumors. ${ }^{121}$

Yao et al developed a neovasculature and CTC dualtargeting nanoplatform (dTNP) by simultaneously conjugating K237 peptide and Ep23 aptamer to the surface of paclitaxel (Ptx)-loaded biodegradable PEG-PLA polymeric micelles. ${ }^{178} \mathrm{~K} 237$ peptide is a 12 -mer peptide isolated by phage display binding specifically and tightly to KDR/ Flk1 tyrosine kinase (one of the two receptors for VEGF overexpressed on tumor neovasculature) and damages vasculogenic mimicry channels. Ep23 is an RNA aptamer with high affinity to EpCAM that is highly expressed on most carcinomas, and it has been reported that it is more sensitive than an antibody in clinical EpCAM detection. The robust CTC-capture and -neutralization capability of 
dTNP was confirmed by cone-plate viscometry in vitro and 4T1-GFP cell-derived lung-metastasis mouse model via in vivo flow cytometry. The in vivo antitumor efficacy of Ptxloaded dTNP was evaluated in orthotropic tumor-bearing mice, and the results indicated that dTNP-Ptx displayed optimal therapeutic efficacy. This tumor neovasculature and CTC dual-targeting nanoscale drug-delivery system provide a new modality for the treatment of metastatic cancers.

\section{Biomimetic nanoplatforms}

In recent years, an emerging new engineering strategy is the fabrication of nature-inspired biomimetic nanosystems that combine synthetic NPs with natural biomaterials. ${ }^{179}$ These nanohybrids incorporate biomimetic characteristics (functionality and complexity) of natural materials into synthetic materials with tailorability and flexibility. ${ }^{180}$ Different from currently used stealth strategies (usually PEG coating) of synthetic materials to escape immune systems, biomimetic nanoplatforms with immunoevasive properties can interact with biological systems without generating immunoresponses. ${ }^{181} \mathrm{Hu}$ et al demonstrated the development of a platelet membrane (PM)-coated core-shell nanovehicle (PM-NV) for tumor targeting and sequential delivery of TRAIL and Dox. ${ }^{182}$ The PM-NV is composed of a nanogel-based inner core for Dox encapsulation and a platelet membrane-based outer shell for TRAIL decoration. TRAIL-Dox-PM-NV dramatically reduced metastatic nodules in MDA-MB-231 xenografttumor mouse model. These results suggest efficient CTC elimination via selective capture by P-selectin on PM and subsequent activation of apoptosis by TRAIL and Dox. In a similar example, synthetic silica particles were functionalized with activated platelet membrane along with surface conjugation of TRAIL, which made the best of CTC adhesion to activated platelets and the tumoricidal effect of immune cells to generate an enhanced therapeutic effect. ${ }^{183}$ In a different case, poly(lactic-co-glycolic acid) NPs coated with an inflammatory neutrophil-derived membrane were loaded with carfilzomib and used for treatment of cancer metastasis. ${ }^{184}$ These carfilzomib-loaded neutrophil-mimicking NPs hold great therapeutic potential for preventing early metastasis, as well as inhibiting the already-formed metastasis via specific elimination of CTCs in the blood. He et al established an inflammatory monocyte-based intelligent biomimetic drug-delivery system with SMNPs by incorporating legumain-responsive NPs into inflammatory monocytes. ${ }^{185}$ Interestingly, the authors noted that inflammatory monocyte MNPs could be delivered efficiently to metastatic sites in the lung, leading to obvious inhibition of lung metastases.

\section{Conclusion}

During the last 6 years, nanotechnological applications received great attention for enrichment, capture, detection, and elimination of CTCs. Applications of engineered NMs in nanomedicine play an important role in early cancer diagnosis and efficient treatment of cancer. The analysis of captured CTCs from patients' peripheral blood samples provides important information about the biology of cancer micrometastasis and shows acceptable application in the clinical management of carcinoma patients. The value of CTC analysis can be demonstrated by liquid biopsies from blood samples of patients with an advanced cancer disease. $^{3}$

For over a decade, the FDA-approved CellSearch system has been successfully used for CTC enumeration. Preliminary results of CTC enumeration and analysis suggest monitoring the drug efficiency and the antitumor activity of an ongoing therapy. Today, numerous different CTC-capture and -detection assays have been developed for screening a range of distinct tumor types at different disease stages. The isolation and detection of CTCs can be very challenging, due to their extremely rare presence within the blood. Therefore, specificity and sensitivity remain the key issues that upcoming technologies need to address. NMs seem to meet these criteria and solve the challenges of insufficient purity and low capture efficiency of CTCs, due to their unique properties. The possibility of multiplexed targeting can be implemented by NMs, because they can be modified with different targeting ligands to capture, isolate, and detect CTC subpopulations.

In this review, different NM-based enrichment, capture, and detection methods have been discussed with respect to their advantages and disadvantages for CTC detection and therapeutic targeting (Table 2). The incorporation of NMs with microfluidic devices combines the benefits of nanotechnology and microchip technology to optimize CTC-capture methods for further analysis. CTCs represent a promising therapeutic target for nanomedicine. Therefore, it is important to detect and analyze patient blood samples and allow patients to undergo targeted CTC therapy to eliminate CTCs in peripheral blood. Conclusive anticancer-therapy efficacy can be monitored steadily via CTC detection and used in guiding anticancer treatment, implementing the idea of nanomedicine: "Small is smarter". 
Table 2 Overview of NP-based CTC detection methods

\begin{tabular}{|c|c|c|c|}
\hline Nanomaterial & Pros & Cons & References \\
\hline MNPs/nanoclusters & Biocompatibility, magnetic separation, high sensitivity & $\begin{array}{l}\text { Magnetic aggregation; dependence } \\
\text { on binding capacity of MNPs (affinity- } \\
\text { based) }\end{array}$ & $42,109-112$ \\
\hline Fe-core MNPs & High magnetic moments, superparamagnetic & $\begin{array}{l}\text { Rapid oxidation } \rightarrow \text { protective shells } \\
\text { needed }\end{array}$ & 57 \\
\hline $\begin{array}{l}\text { Magnetic-optical } \\
\text { bifunctional NPs }\end{array}$ & $\begin{array}{l}\text { Simultaneous detection and isolation of various tumor-cell } \\
\text { types, killing by } \mathrm{X} \text {-ray-based detection possible }\end{array}$ & Affinity-based & 53 \\
\hline Micro-NMR & $\begin{array}{l}\text { Rapid, highly sensitive biomarker detection, only minimal } \\
\text { sample purification necessary }\end{array}$ & $\begin{array}{l}\text { Variation in NMR frequency depending } \\
\text { on temperature }\end{array}$ & 57 \\
\hline Quantum dots & $\begin{array}{l}\text { Quantitative detection with high sensitivity, various } \\
\text { fluorescence types enable capture of heterogeneous CTCs }\end{array}$ & $\begin{array}{l}\text { Toxicity affects viability (no further } \\
\text { investigations possible), intermittence } \\
\text { under continuous excitation }\end{array}$ & 21,53 \\
\hline Gold NPs & $\begin{array}{l}\text { Microsurgical removal/laser-controlled detection and } \\
\text { direct ablation of CTCs, postcapture analysis }\end{array}$ & $\begin{array}{l}\text { Nonbiodegradability, complicated } \\
\text { preparation }\end{array}$ & $21,53,113,114$ \\
\hline $\begin{array}{l}\text { Graphene/graphene } \\
\text { oxides }\end{array}$ & $\begin{array}{l}\text { High specificity, multiplex functionalization, label-free } \\
\text { detection, high conductivity, no toxicity, easy } \\
\text { functionalization }\end{array}$ & $\begin{array}{l}\text { Aspecific cellular internalization, hybrid } \\
\text { sensors not reproducible yet }\end{array}$ & $\begin{array}{l}21,53,92 \\
115-118\end{array}$ \\
\hline Liposomes & Biocompatibility, long blood-circulation time & Low stability & $21,119,120$ \\
\hline $\begin{array}{l}\text { Polymeric } \\
\text { nanomaterials }\end{array}$ & $\begin{array}{l}\text { Biocompatibility and biodegradability, ease of chemical } \\
\text { modification, drug encapsulation/conjugation, improves } \\
\text { sensitivity/selectivity of surfaces for CTC detection }\end{array}$ & Low stability & $53,97,121$ \\
\hline Hybrid NPs & Recovery of viable cells, can proliferate in vitro & $\begin{array}{l}\text { Different hybrid NPs for different } \\
\text { types of CTCs necessary, all trials still } \\
\text { in vitro }\end{array}$ & 100 \\
\hline SWCNTs/MWCNTs & $\begin{array}{l}\text { High stability, bioactivity, capable of cell capture, high } \\
\text { sensitivity, even in whole blood }\end{array}$ & $\begin{array}{l}\text { One type of aptamer binds only one } \\
\text { specific target }\end{array}$ & 122 \\
\hline $\begin{array}{l}\text { Microfabricated } \\
\text { filters }\end{array}$ & Label-free, unbiased & Sensitivity to size & 12,42 \\
\hline $\begin{array}{l}\text { Microfluidic-enabled } \\
\text { immunoseparation }\end{array}$ & $\begin{array}{l}\text { High efficiency, sensitivity, throughput, automatic, further } \\
\text { molecular analysis }\end{array}$ & $\begin{array}{l}\text { Relied on microscopy imaging for CTC } \\
\text { identification after isolation }\end{array}$ & $12,36,42,65,123$ \\
\hline Herringbone chip & Transparent device for better imaging & & $12,36,116$ \\
\hline CTC chip & $\begin{array}{l}\text { High throughput, combination of immunomagnetic sorting } \\
\text { with micropost-based enrichment }\end{array}$ & & $12,36,116,124$ \\
\hline Micro-Hall detector & $\begin{array}{l}\text { Rapid detection, high contrast against blood cells, } \\
\text { detection of multiple biomarkers }\end{array}$ & Limited throughput (about $10^{7}$ cells) & 124,125 \\
\hline Gilupi nanodetector & Large volume analyzed & Affinity-based, complex procedure & 12,36 \\
\hline
\end{tabular}

Note: Data from Zhang and King. ${ }^{2 !}$

Abbreviations: MNPs, magnetic nanoparticles; CTC, circulating tumor cell; SWCNTs, single-walled carbon nanotubes; MWCNTs, multiwalled CNTs; NMR, nuclear magnetic resonance; NP, nanoparticle.

\section{Acknowledgments}

This work was supported by grants from the Research Center for Natural and Medical Sciences ([Naturwissenschaftlichmedizinisches Forschungszentrum]; NMFZ), Impulse Fund Rhineland Palatinate, Brigitte and Dr Konstanze Wegener Foundation, German Research Foundation ([Deutsche Forschungsgemeinschaft]; DFG) and NanoTransMed, which is co-funded by the European Regional Development Fund (ERDF) in the framework of the Interreg V Upper Rhine program, the Swiss Confederation, and the Swiss cantons of Aargau, Basel-Landschaft, and Basel-Stadt.

\section{Author contributions}

All authors contributed toward data analysis, drafting and critically revising the paper, gave final approval of the version to be published, and agree to be accountable for all aspects of the work.

\section{Disclosure}

The authors report no conflicts of interest in this work.

\section{References}

1. Docter D, Westmeier D, Markiewicz M, Stolte S, Knauer SK, Stauber RH. The nanoparticle biomolecule corona: lessons learned challenge accepted? Chem Soc Rev. 2015;44(17):6094-6121. doi:10.1039/ c5 $\operatorname{cs} 00217 f$

2. Mocellin S, Hoon D, Ambrosi A, Nitti D, Rossi CR. The prognostic value of circulating tumor cells in patients with melanoma: a systematic review and meta-analysis. Clin Cancer Res. 2006;12(15):4605-4613. doi:10.1158/1078-0432.CCR-06-0823

3. Pantel K, Alix-Panabieres C. Circulating tumour cells in cancer patients: challenges and perspectives. Trends Mol Med. 2010;16(9):398-406. doi:10.1016/j.molmed.2010.07.001 
4. Kramer OH, Stauber RH, Bug G, Hartkamp J, Knauer SK. SIAH proteins: critical roles in leukemogenesis. Leukemia. 2013;27(4):792-802. doi:10.1038/leu.2012.284

5. Garzia L, D'Angelo A, Amoresano A, et al. Phosphorylation of nm23$\mathrm{H} 1$ by $\mathrm{CKI}$ induces its complex formation with h-prune and promotes cell motility. Oncogene. 2008;27(13):1853-1864. doi:10.1038/sj. onc. 1210822

6. Hong Y, Fang F, Zhang Q. Circulating tumor cell clusters: what we know and what we expect (Review). Int J Oncol. 2016;49(6):2206-2216. doi:10.3892/ijo.2016.3747

7. Lambert AW, Pattabiraman DR, Weinberg RA. Emerging biological principles of metastasis. Cell. 2017;168(4):670-691. doi:10.1016/j.cell. 2016.11.037

8. Nguyen DX, Bos PD, Massague J. Metastasis: from dissemination to organ-specific colonization. Nat Rev Cancer. 2009;9(4):274-284. doi: $10.1038 / \mathrm{nrc} 2622$

9. Austin RG, Huang TJ, Wu M, Armstrong AJ, Zhang T. Clinical utility of non-EpCAM based circulating tumor cell assays. Adv Drug Deliv Rev. 2018;125:132-142. doi:10.1016/j.addr.2018.01.013

10. Allard WJ, Matera J, Miller MC, et al. Tumor cells circulate in the peripheral blood of all major carcinomas but not in healthy subjects or patients with nonmalignant diseases. Clin Cancer Res. 2004;10(20): 6897-6904. doi:10.1158/1078-0432.CCR-04-0378

11. Kim S, Han SI, Park MJ, et al. Circulating tumor cell microseparator based on lateral magnetophoresis and immunomagnetic nanobeads. Anal Chem. 2013;85(5):2779-2786. doi:10.1021/ac303284u

12. Pantel K, Brakenhoff RH, Brandt B. Detection, clinical relevance and specific biological properties of disseminating tumour cells. Nat Rev Cancer. 2008;8(5):329-340. doi:10.1038/nrc2375

13. Hao SJ, Wan Y, Xia YQ, Zou X, Zheng SY. Size-based separation methods of circulating tumor cells. Adv Drug Deliv Rev. 2018. doi:10.1016/j. addr.2018.01.002

14. Jaeger BA, Jueckstock J, Andergassen U, et al. Evaluation of two different analytical methods for circulating tumor cell detection in peripheral blood of patients with primary breast cancer. Biomed Res Int. 2014; 2014:491459. doi:10.1155/2014/491459

15. Murray NP, Albarran V, Perez G, Villalon R, Ruiz A. Secondary circulating tumor cells (CTCs) but not primary CTCs are associated with the clinico-pathological parameters in chilean patients with colorectal cancer. Asian Pac J Cancer Prev. 2015;16(11):4745-4749.

16. Wendel M, Bazhenova L, Boshuizen R, et al. Fluid biopsy for circulating tumor cell identification in patients with early- and late-stage nonsmall cell lung cancer: a glimpse into lung cancer biology. Phys Biol. 2012;9(1):016005. doi:10.1088/1478-3967/9/1/016005

17. Engel H, Kleespies C, Friedrich J, et al. Detection of circulating tumour cells in patients with breast or ovarian cancer by molecular cytogenetics. Br J Cancer. 1999;81(7):1165-1173. doi:10.1038/sj.bjc.6690825

18. de Bono JS, Scher HI, Montgomery RB, et al. Circulating tumor cells predict survival benefit from treatment in metastatic castration-resistant prostate cancer. Clin Cancer Res. 2008;14(19):6302-6309. doi:10. 1158/1078-0432.CCR-08-0872

19. Ried K, Eng P, Sali A. Screening for circulating tumour cells allows early detection of cancer and monitoring of treatment effectiveness: an observational study. Asian Pac J Cancer Prev. 2017;18(8): 2275-2285. doi:10.22034/APJCP.2017.18.8.2275

20. Bhana S, Wang Y, Huang X. Nanotechnology for enrichment and detection of circulating tumor cells. Nanomedicine (Lond). 2015;10(12): 1973-1990. doi:10.2217/nnm.15.32

21. Zhang Z, King MR. Nanomaterials for the capture and therapeutic targeting of circulating tumor cells. Cell Mol Bioeng. 2017;10(4):275-294. doi:10.1007/s12195-017-0497-4

22. Satelli A, Mitra A, Brownlee Z, et al. Epithelial-mesenchymal transitioned circulating tumor cells capture for detecting tumor progression. Clin Cancer Res. 2015;21(4):899-906. doi:10.1158/1078-0432. CCR-14-0894

23. Ashworth TR. A case of cancer in which cells similar to those in the tumors were seen in the blood after death. Australas Med J. 1869;14: $146-149$.
24. Arya SK, Lim B, Rahman AR. Enrichment, detection and clinical significance of circulating tumor cells. Lab Chip. 2013;13(11):1995-2027. doi: $10.1039 / \mathrm{c} 31 \mathrm{c} 00009 \mathrm{e}$

25. Rauscher H, Sokull-Kluttgen B, Stamm H. The European Commission's recommendation on the definition of nanomaterial makes an impact. Nanotoxicology. 2013;7(7):1195-1197. doi:10.3109/17435390.2012. 724724

26. Toss A, Mu Z, Fernandez S, Cristofanilli M. CTC enumeration and characterization: moving toward personalized medicine. Ann Transl Med. 2014;2(11):108

27. Ming Y, Li Y, Xing H, et al. Circulating tumor cells: from theory to nanotechnology-based detection. Front Pharmacol. 2017;8:35.

28. Clevers $H$. The cancer stem cell: premises, promises and challenges. Nat Med. 2011;17(3):313-319. doi:10.1038/nm.2304

29. Aceto N, Bardia A, Miyamoto DT, et al. Circulating tumor cell clusters are oligoclonal precursors of breast cancer metastasis. Cell. 2014;158(5):1110-1122. doi:10.1016/j.cell.2014.07.013

30. Wollenberg B. Implication of stem cells in the biology and therapy of head and neck cancer. GMS Curr Top Otorhinolaryngol Head Neck Surg. 2011;10:Doc01.

31. Krawczyk N, Meier-Stiegen F, Banys M, Neubauer H, Ruckhaeberle E, Fehm T. Expression of stem cell and epithelial-mesenchymal transition markers in circulating tumor cells of breast cancer patients. Biomed Res Int. 2014;2014:415721. doi:10.1155/2014/415721

32. Massague J, Obenauf AC. Metastatic colonization by circulating tumour cells. Nature. 2016;529(7586):298-306. doi:10.1038/nature17038

33. Nieto MA. Epithelial plasticity: a common theme in embryonic and cancer cells. Science. 2013;342(6159):1234850. doi:10.1126/science. 1234850

34. Mani SA, Guo W, Liao MJ, et al. The epithelial-mesenchymal transition generates cells with properties of stem cells. Cell. 2008;133(4):704-715. doi:10.1016/j.cell.2008.03.027

35. Lippert BM, Knauer SK, Fetz V, Mann W, Stauber RH. Dynamic survivin in head and neck cancer: molecular mechanism and therapeutic potential. Int J Cancer. 2007;121(6):1169-1174. doi:10.1002/ijc.22941

36. Alix-Panabieres C, Pantel K. Technologies for detection of circulating tumor cells: facts and vision. Lab Chip. 2014;14(1):57-62. doi:10.1039/ c31c50644d

37. Shen Z. Cancer biomarkers and targeted therapies. Cell Biosci. 2013; 3(1):6. doi:10.1186/2045-3701-3-6

38. Knauer SK, Stauber RH. Development of an autofluorescent translocation biosensor system to investigate protein-protein interactions in living cells. Anal Chem. 2005;77(15):4815-4820. doi:10.1021/ ac050413o

39. Alix-Panabieres C, Pantel K. Challenges in circulating tumour cell research. Nat Rev Cancer. 2014;14(9):623-631. doi:10.1038/nrc3820

40. Opoku-Damoah Y, Assanhou AG, Sooro MA, Baduweh CA, Sun C. Functional diagnostic and therapeutic nanoconstructs for efficient probing of circulating tumor cells. ACS Appl Mater Interfaces. 2018; 10(17):14231-14247. doi:10.1021/acsami.7b17896

41. Raimondi C, Gradilone A, Naso G, Cortesi E, Gazzaniga P. Clinical utility of circulating tumor cell counting through CellSearch $((\mathrm{R}))$ : the dilemma of a concept suspended in Limbo. Onco Targets Ther. 2014;7: 619-625. doi:10.2147/OTT.S46200

42. Zhang J, Chen K, Fan ZH. Circulating tumor cell isolation and analysis. Adv Clin Chem. 2016;75:1-31. doi:10.1016/bs.acc.2016.03.003

43. Wang H, Lin Y, Nienhaus K, Nienhaus GU. The protein corona on nanoparticles as viewed from a nanoparticle-sizing perspective. Wiley Interdiscip Rev Nanomed Nanobiotechnol. 2018;10(4):e1500.

44. Monopoli MP, Aberg C, Salvati A, Dawson KA. Biomolecular coronas provide the biological identity of nanosized materials. Nat Nanotechnol. 2012;7(12):779-786. doi:10.1038/nnano.2012.207

45. Monopoli MP, Bombelli FB, Dawson KA. Nanobiotechnology: nanoparticle coronas take shape. Nat Nanotechnol. 2011;6(1):11-12. doi:10.1038/nnano.2011.267

46. Tenzer S, Docter D, Kuharev J, et al. Rapid formation of plasma protein corona critically affects nanoparticle pathophysiology. Nat Nanotechnol. 2013;8(10):772-781. doi:10.1038/nnano.2013.181 
47. Treuel L, Docter D, Maskos M, Stauber RH. Protein corona-from molecular adsorption to physiological complexity. Beilstein J Nanotechnol. 2015;6:857-873. doi:10.3762/bjnano.6.88

48. Vroman L. Effect of absorbed proteins on the wettability of hydrophilic and hydrophobic solids. Nature. 1962;196:476-477.

49. Cedervall T, Lynch I, Lindman S, et al. Understanding the nanoparticleprotein corona using methods to quantify exchange rates and affinities of proteins for nanoparticles. Proc Natl Acad Sci U S A. 2007;104(7): 2050-2055. doi:10.1073/pnas.0608582104

50. Westmeier D, Stauber RH, Docter D. The concept of bio-corona in modulating the toxicity of engineered nanomaterials (ENM). Toxicol Appl Pharmacol. 2016;299:53-57. doi:10.1016/j.taap.2015.11.008

51. Walczyk D, Bombelli FB, Monopoli MP, Lynch I, Dawson KA. What the cell "sees" in bionanoscience. J Am Chem Soc. 2010;132(16): 5761-5768. doi:10.1021/ja910675v

52. Walkey CD, Olsen JB, Song F, et al. Protein corona fingerprinting predicts the cellular interaction of gold and silver nanoparticles. ACS Nano. 2014;8(3):2439-2455. doi:10.1021/nn406018q

53. Myung JH, Tam KA, Park SJ, Cha A, Hong S. Recent advances in nanotechnology-based detection and separation of circulating tumor cells. Wiley Interdiscip Rev Nanomed Nanobiotechnol. 2016;8(2): 223-239. doi:10.1002/wnan.1360

54. Huang Q, Wang Y, Chen X, et al. Nanotechnology-based strategies for early cancer diagnosis using circulating tumor cells as a liquid biopsy. Nanotheranostics. 2018;2(1):21-41. doi:10.7150/ntno.22091

55. Mahmoudi M, Sant S, Wang B, Laurent S, Sen T. Superparamagnetic iron oxide nanoparticles (SPIONs): development, surface modification and applications in chemotherapy. Adv Drug Deliv Rev. 2011;63(1-2): 24-46. doi:10.1016/j.addr.2010.05.006

56. Ding C, Zhang C, Yin X, Cao X, Cai M, Xian Y. Near-infrared fluorescent $\mathrm{Ag} 2 \mathrm{~S}$ nanodot-based signal amplification for efficient detection of circulating tumor cells. Anal Chem. 2018;90(11):6702-6709. doi:10. 1021/acs.analchem.8b00514

57. Castro CM, Ghazani AA, Chung J, et al. Miniaturized nuclear magnetic resonance platform for detection and profiling of circulating tumor cells. Lab Chip. 2014;14(1):14-23. doi:10.1039/c3lc50621e

58. Lee H, Sun E, Ham D, Weissleder R. Chip-NMR biosensor for detection and molecular analysis of cells. Nat Med. 2008;14(8):869-874. doi: $10.1038 / \mathrm{nm} .1711$

59. Riethdorf S, O'Flaherty L, Hille C, Pantel K. Clinical applications of the CellSearch platform in cancer patients. Adv Drug Deliv Rev. 2018;125:102-121. doi:10.1016/j.addr.2018.01.011

60. Pamme N. Magnetism and microfluidics. Lab Chip. 2006;6(1):24-38. doi:10.1039/b513005k

61. Rao CG, Chianese D, Doyle GV, et al. Expression of epithelial cell adhesion molecule in carcinoma cells present in blood and primary and metastatic tumors. Int J Oncol. 2005;27(1):49-57.

62. Andreopoulou E, Yang LY, Rangel KM, et al. Comparison of assay methods for detection of circulating tumor cells in metastatic breast cancer: adnaGen adnatest breastcancer select/detect versus veridex cellsearch system. Int J Cancer. 2012;130(7):1590-1597. doi:10.1002/ijc.26111

63. Gorges TM, Tinhofer I, Drosch M, et al. Circulating tumour cells escape from EpCAM-based detection due to epithelial-to-mesenchymal transition. BMC Cancer. 2012;12:178. doi:10.1186/1471-2407-12-178

64. Jia Z, Liang Y, Xu X, et al. Isolation and characterization of human mesenchymal stem cells derived from synovial fluid by magnetic-activated cell sorting (MACS). Cell Biol Int. 2018;42(3):262-271. doi:10.1002/cbin.10903

65. Yang L, Lang JC, Balasubramanian P, et al. Optimization of an enrichment process for circulating tumor cells from the blood of head and neck cancer patients through depletion of normal cells. Biotechnol Bioeng. 2009;102(2):521-534. doi:10.1002/bit.22066

66. Cai W, Gao T, Hong H, Sun J. Applications of gold nanoparticles in cancer nanotechnology. Nanotechnol Sci Appl. 2008;1:17-32.

67. Wu X, Xia Y, Huang Y, et al. Improved SERS-active nanoparticles with various shapes for CTC detection without enrichment process with supersensitivity and high specificity. ACS Appl Mater Interfaces. 2016; 8(31):19928-19938. doi:10.1021/acsami.6b07205
68. Hu M, Chen J, Li ZY, et al. Gold nanostructures: engineering their plasmonic properties for biomedical applications. Chem Soc Rev. 2006;35(11):1084-1094. doi:10.1039/b517615h

69. Huang X, Jain PK, El-Sayed IH, El-Sayed MA. Gold nanoparticles: interesting optical properties and recent applications in cancer diagnostics and therapy. Nanomedicine (Lond). 2007;2(5):681-693. doi:10. 2217/17435889.2.5.681

70. Galanzha EI, Viegas MG, Malinsky TI, et al. In vivo acoustic and photoacoustic focusing of circulating cells. Sci Rep. 2016;6:21531. doi:10.1038/srep21531

71. He W, Wang H, Hartmann LC, Cheng JX, Low PS. In vivo quantitation of rare circulating tumor cells by multiphoton intravital flow cytometry. Proc Natl Acad Sci U S A. 2007;104(28):11760-11765. doi:10.1073/ pnas.0703875104

72. He B, Yang D, Qin M, et al. Increased cellular uptake of peptidemodified PEGylated gold nanoparticles. Biochem Biophys Res Commun. 2017;494(1-2):339-345. doi:10.1016/j.bbrc.2017.10.026

73. Zhang Y, Kohler N, Zhang M. Surface modification of superparamagnetic magnetite nanoparticles and their intracellular uptake. Biomaterials. 2002;23(7):1553-1561.

74. Li W, Chen X. Gold nanoparticles for photoacoustic imaging. Nanomedicine (Lond). 2015;10(2):299-320. doi:10.2217/nnm. 14.169

75. Song J, Kim J, Hwang S, et al. "Smart" gold nanoparticles for photoacoustic imaging: an imaging contrast agent responsive to the cancer microenvironment and signal amplification via $\mathrm{pH}$-induced aggregation. Chem Commun (Camb). 2016;52(53):8287-8290. doi:10.1039/ c6cc03100e

76. Zhang YJ, Zeng QY, Li LF, et al. Label-free rapid identification of tumor cells and blood cells with silver film SERS substrate. Opt Express. 2018;26(25):33044-33056. doi:10.1364/OE.26.033044

77. Galanzha EI, Zharov VP. Circulating tumor cell detection and capture by photoacoustic flow cytometry in vivo and ex vivo. Cancers (Basel). 2013;5(4):1691-1738. doi:10.3390/cancers5041691

78. Park MH, Reategui E, Li W, et al. Enhanced isolation and release of circulating tumor cells using nanoparticle binding and ligand exchange in a microfluidic chip. J Am Chem Soc. 2017;139(7):2741-2749. doi:10. 1021/jacs.6b12236

79. Yu M, Stott S, Toner M, Maheswaran S, Haber DA. Circulating tumor cells: approaches to isolation and characterization. J Cell Biol. 2011; 192(3):373-382. doi:10.1083/jcb.201010021

80. Rosorius O, Heger P, Stelz G, Hirschmann N, Hauber J, Stauber RH. Direct observation of nucleocytoplasmic transport by microinjection of GFP-tagged proteins in living cells. Biotechniques. 1999;27(2):350-355. doi:10.2144/99272rr02

81. Lee J, Kang HJ, Jang H, et al. Simultaneous imaging of two different cancer biomarkers using aptamer-conjugated quantum dots. Sensors (Basel). 2015;15(4):8595-8604. doi:10.3390/s150408595

82. Zhang H, Fu X, Hu J, Zhu Z. Microfluidic bead-based multienzymenanoparticle amplification for detection of circulating tumor cells in the blood using quantum dots labels. Anal Chim Acta. 2013;779:64-71. doi:10.1016/j.aca.2013.03.060

83. Aboulaich A, Tilmaciu CM, Merlin C, et al. Physicochemical properties and cellular toxicity of (poly)aminoalkoxysilanes-functionalized $\mathrm{ZnO}$ quantum dots. Nanotechnology. 2012;23(33):335101. doi:10. 1088/0957-4484/23/33/335101

84. Clapp AR, Medintz IL, Mauro JM, Fisher BR, Bawendi MG, Mattoussi H. Fluorescence resonance energy transfer between quantum dot donors and dye-labeled protein acceptors. J Am Chem Soc. 2004; 126(1):301-310. doi:10.1021/ja037088b

85. Guo S, Chen YQ, Lu NN, Wang XY, Xie M, Sui WP. Ultrasonicationassisted one-step self-assembly preparation of biocompatible fluorescentmagnetic nanobeads for rare cancer cell detection. Nanotechnology. 2014;25(50):505603. doi:10.1088/0957-4484/25/50/505603

86. Hossain M, Luo Y, Sun Z, et al. X-ray enabled detection and eradication of circulating tumor cells with nanoparticles. Biosens Bioelectron. 2012;38(1):348-354. doi:10.1016/j.bios.2012.06.020 
87. Song EQ, Hu J, Wen CY, et al. Fluorescent-magnetic-biotargeting multifunctional nanobioprobes for detecting and isolating multiple types of tumor cells. ACS Nano. 2011;5(2):761-770. doi:10.1021/ nn 1011336

88. Kim JH, Chung HH, Jeong MS, Song MR, Kang KW, Kim JS. One-step detection of circulating tumor cells in ovarian cancer using enhanced fluorescent silica nanoparticles. Int J Nanomedicine. 2013;8:2247-2257. doi:10.2147/IJN.S45059

89. Tan J, Yang N, Hu Z, et al. Aptamer-functionalized fluorescent silica nanoparticles for highly sensitive detection of leukemia cells. Nanoscale Res Lett. 2016;11(1):298. doi:10.1186 s11671-016-1512-8

90. Pramani KA, Jones S, Gao Y, et al. Multifunctional hybrid graphene oxide for circulating tumor cell isolation and analysis. Adv Drug Deliv Rev 2018;125:21-35. doi:10.1016/j.addr.2018.01.004

91. Yoon HJ, Kozminsky M, Nagrath S. Emerging role of nanomaterials in circulating tumor cell isolation and analysis. ACS Nano. 2014;8(3): 1995-2017. doi:10.1021/nn5004277

92. Yoon HJ, Kim TH, Zhang Z, et al. Sensitive capture of circulating tumour cells by functionalized graphene oxide nanosheets. Nat Nanotechnol. 2013;8(10):735-741. doi:10.1038/ nnano.2013.194

93. Dreyer DR, Park S, Bielawski CW, Ruoff RS. The chemistry of graphene oxide. Chem Soc Rev. 2010;39(1):228-240. doi:10.1039/b917103g

94. Sun X, Liu Z, Welsher K, et al. Nano-graphene oxide for cellular imaging and drug delivery. Nano Res. 2008;1(3):203-212. doi:10.1016/j. jelechem.2017.12.012

95. Loh KP, Bao Q, Eda G, Chhowalla M. Graphene oxide as a chemically tunable platform for optical applications. Nat Chem. 2010;2(12) 1015-1024. doi:10.1038/nchem.907

96. Wu Y, Xue P, Kang Y, Hui KM. Highly specific and ultrasensitive graphene-enhanced electrochemical detection of low-abundance tumor cells using silica nanoparticles coated with antibody-conjugated quantum dots. Anal Chem. 2013;85(6):3166-3173. doi:10.1021/ac303398b

97. Myung JH, Gajjar KA, Saric J, Eddington DT, Hong S. Dendrimermediated multivalent binding for the enhanced capture of tumor cells. Angew Chem Int Ed Engl. 2011;50(49):11769-11772. doi:10.1002/ anie. 201105508

98. Wei Z, Barlow DE, Sheehan PE. The assembly of single-layer graphene oxide and graphene using molecular templates. Nano Lett. 2008;8(10): 3141-3145. doi:10.1021/n1801301a

99. Tian L, Qi JX, Qian K, et al. Copper (II) oxide nanozyme based electrochemical cytosensor for high sensitive detection of circulating tumor cells in breast cancer. J Electroanal Chem. 2018;812:1-9. doi:10.1016/j.jelechem.2017.12.012

100. Lee HJ, Cho HY, Oh JH, et al. Simultaneous capture and in situ analysis of circulating tumor cells using multiple hybrid nanoparticles. Biosens Bioelectron. 2013;47:508-514. doi:10.1016/j.bios.2013.03.040

101. Zylstra J, Alam R, Han H, Doyle RP, Maye MM. Tailoring quantum dot interfaces for improved biofunctionality and energy transfer. Functional Nanoparticles for Bioanalysis, Nanomedicine, and Bioelectronic Devices. ACS Symposium Series. 1112: American Chemical Society. 2012;1:59-79.

102. Murray AR, Kisin ER, Tkach AV, et al. Factoring-in agglomeration of carbon nanotubes and nanofibers for better prediction of their toxicity versus asbestos. Part Fibre Toxicol. 2012;9:10. doi:10.1186/ 1743-8977-9-10

103. De Jong KP, Geus JW. Carbon nanofibers: catalytic synthesis and applications. Catal Rev Sci Eng. 2000;42(4):481-510. doi:10.1081/ CR-100101954

104. Allegri M, Perivoliotis DK, Bianchi MG, et al. Toxicity determinants of multi-walled carbon nanotubes: the relationship between functionalization and agglomeration. Toxicol Rep. 2016;3:230-243. doi:10.1016/j. toxrep.2016.01.011

105. Shao N, Wickstrom E, Panchapakesan B. Nanotube-antibody biosensor arrays for the detection of circulating breast cancer cells. Nanotechnology. 2008;19(46):465101. doi:10.1088/0957-4484/19/46/465101
106. Liu Y, Zhu F, Dan W, Fu Y, Liu S. Construction of carbon nanotube based nanoarchitectures for selective impedimetric detection of cancer cells in whole blood. Analyst. 2014;139(20):5086-5092. doi:10.1039/ c4an00758a

107. Tan SJ, Yobas L, Lee GY, Ong CN, Lim CT. Microdevice for the isolation and enumeration of cancer cells from blood. Biomed Microdevices. 2009;11(4):883-892. doi:10.1007/s10544-009-9305-9

108. Zheng S, Lin H, Liu JQ, et al. Membrane microfilter device for selective capture, electrolysis and genomic analysis of human circulating tumor cells. J Chromatogr A . 2007;1162(2):154-161. doi:10.1016/j. chroma.2007.05.064

109. Balasubramanian P, Lang JC, Jatana KR, et al. Multiparameter analysis, including EMT markers, on negatively enriched blood samples from patients with squamous cell carcinoma of the head and neck. PLoS One. 2012;7(7):e42048. doi:10.1371/journal.pone.0042048

110. Grisanti S, Almici C, Consoli F, et al. Circulating tumor cells in patients with recurrent or metastatic head and neck carcinoma: prognostic and predictive significance. PLoS One. 2014;9(8):e103918. doi:10.1371/ journal.pone. 0103918

111. Lin $\mathrm{HC}$, $\mathrm{Hsu} \mathrm{HC}$, Hsieh $\mathrm{CH}$, et al. A negative selection system PowerMag for effective leukocyte depletion and enhanced detection of EpCAM positive and negative circulating tumor cells. Clin Chim Acta. 2013;419:77-84. doi:10.1016/j.cca.2013.01.018

112. Lustberg M, Jatana KR, Zborowski M, Chalmers JJ. Emerging technologies for CTC detection based on depletion of normal cells. Recent Results Cancer Res. 2012;195:97-110. doi:10.1007/ 978-3-642-28160-0_9

113. Galanzha EI, Shashkov E, Sarimollaoglu M, et al. In vivo magnetic enrichment, photoacoustic diagnosis, and photothermal purging of infected blood using multifunctional gold and magnetic nanoparticles. PLoS One. 2012;7(9):e45557. doi:10.1371/journal.pone.0045557

114. Galanzha EI, Zharov VP. Photoacoustic flow cytometry. Methods. 2012;57(3):280-296. doi:10.1016/j.ymeth.2012.06.009

115. Cruz SM, Girao AF, Goncalves G, Marques PA. Graphene: the missing piece for cancer diagnosis? Sensors (Basel). 2016;16(1):137. doi: $10.3390 / \mathrm{s} 16122100$

116. Ferreira MM, Ramani VC, Jeffrey SS. Circulating tumor cell technologies. Mol Oncol. 2016;10(3):374-394. doi:10.1016/j.molonc.2016.01.007

117. Li Y, Lu Q, Liu H, et al. Antibody-modified reduced graphene oxide films with extreme sensitivity to circulating tumor cells. Adv Mater. 2015;27(43):6848-6854. doi:10.1002/adma.201502615

118. Yin PT, Kim TH, Choi JW, Lee KB. Prospects for graphene-nanoparticlebased hybrid sensors. Phys Chem Chem Phys. 2013;15(31):12785-12799. doi:10.1039/c3ep51901e

119. Chandrasekaran S, Chan MF, Li J, King MR. Super natural killer cells that target metastases in the tumor draining lymph nodes. Biomaterials. 2016;77:66-76. doi:10.1016/j.biomaterials.2015.11.001

120. Mitchell MJ, Wayne E, Rana K, Schaffer CB, King MR. TRAIL-coated leukocytes that kill cancer cells in the circulation. Proc Natl Acad Sci US A. 2014;111(3):930-935. doi:10.1073/pnas.1316312111

121. Deng S, Wu Q, Zhao Y, et al. Biodegradable polymeric micelleencapsulated doxorubicin suppresses tumor metastasis by killing circulating tumor cells. Nanoscale. 2015;7(12):5270-5280. doi:10.1039/ c4nr07641a

122. Liu H, Xu S, He Z, Deng A, Zhu JJ. Supersandwich cytosensor for selective and ultrasensitive detection of cancer cells using aptamerDNA concatamer-quantum dots probes. Anal Chem. 2013;85(6): 3385-3392. doi:10.1021/ac303789x

123. Casavant BP, Mosher R, Warrick JW, et al. A negative selection methodology using a microfluidic platform for the isolation and enumeration of circulating tumor cells. Methods. 2013;64(2):137-143. doi:10.1016/j.ymeth.2013.05.027

124. Alix-Panabieres C, Pantel K. Circulating tumor cells: liquid biopsy of cancer Clin Chem. 2013;59(1):110-118. doi:10.1373/clinchem.2012.194258

125. Issadore $\mathrm{D}$, Chung J, Shao $\mathrm{H}$, et al. Ultrasensitive clinical enumeration of rare cells ex vivo using a micro-hall detector. Sci Transl Med. 2012; 4(141):141ra92. doi:10.1126/scitranslmed.3003747 
126. Jackson JM, Witek MA, Kamande JW, Soper SA. Materials and microfluidics: enabling the efficient isolation and analysis of circulating tumour cells. Chem Soc Rev. 2017;46(14):4245-4280. doi:10.1039/c7cs00016b

127. Qian W, Zhang Y, Chen W. Capturing Cancer: Emerging microfluidic technologies for the capture and characterization of circulating tumor cells. Small. 2015;11(32):3850-3872. doi:10.1002/smll.201403658

128. Li P, Stratton ZS, Dao M, Ritz J, Huang TJ. Probing circulating tumor cells in microfluidics. Lab Chip. 2013;13(4):602-609. doi:10.1039/ c21c90148j

129. Ortega FG, Fernandez-Baldo MA, Serrano MJ, Messina GA, Lorente JA, Raba J. Epithelial cancer biomarker EpCAM determination in peripheral blood samples using a microfluidic immunosensor based in silver nanoparticles as platform. Sens Actuators B Chem. 2015;221:248-256. doi:10.1016/j.snb.2015.06.066

130. Hoshino K, Huang YY, Lane N, et al. Microchip-based immunomagnetic detection of circulating tumor cells. Lab Chip. 2011;11(20): 3449-3457. doi:10.1039/c1lc20270g

131. Huang YY, Hoshino K, Chen P, et al. Immunomagnetic nanoscreening of circulating tumor cells with a motion controlled microfluidic system. Biomed Microdevices. 2013;15(4):673-681. doi:10.1007/ s10544-012-9718-8

132. Nagrath S, Sequist LV, Maheswaran S, et al. Isolation of rare circulating tumour cells in cancer patients by microchip technology. Nature. 2007;450(7173):1235-1239. doi:10.1038/nature06385

133. Stott SL, Hsu CH, Tsukrov DI, et al. Isolation of circulating tumor cells using a microvortex-generating herringbone-chip. Proc Natl Acad Sci US A. 2010;107(43):18392-18397. doi:10.1073/pnas.1012539107

134. Shi L, Wang K, Yang Y. Adhesion-based tumor cell capture using nanotopography. Colloids Surf B Biointerfaces. 2016;147:291-299. doi:10.1016/j.colsurfb.2016.08.008

135. McCarley RL, Vaidya B, Wei S, et al. Resist-free patterning of surface architectures in polymer-based microanalytical devices. J Am Chem Soc. 2005;127(3):842-843. doi:10.1021/ja0454135

136. Adams AA, Okagbare PI, Feng J, et al. Highly efficient circulating tumor cell isolation from whole blood and label-free enumeration using polymer-based microfluidics with an integrated conductivity sensor. J Am Chem Soc. 2008;130(27):8633-8641. doi:10.1021/ja8015022

137. Barber CJ. Central venous catheter placement for intravenous digital subtraction angiography: an assessment of technical problems and success rate. Br J Radiol. 1989;62(739):599-602. doi:10.1259/0007-1285-62-739-599

138. Gorges TM, Penkalla N, Schalk T, et al. Enumeration and molecular characterization of tumor cells in lung cancer patients using a novel in vivo device for capturing circulating tumor cells. Clin Cancer Res. 2016;22(9):2197-2206. doi:10.1158/1078-0432.CCR-15-1416

139. Saucedo-Zeni N, Mewes S, Niestroj R, et al. A novel method for the in vivo isolation of circulating tumor cells from peripheral blood of cancer patients using a functionalized and structured medical wire. Int J Oncol. 2012;41(4):1241-1250. doi:10.3892/ijo.2012.1557

140. Scherag FD, Niestroj-Pahl R, Krusekopf S, Lucke K, Brandstetter T, Ruhe J. Highly selective capture surfaces on medical wires for fishing tumor cells in whole blood. Anal Chem. 2017;89(3):1846-1854. doi:10.1021/acs.analchem.6b04219

141. Theil G, Fischer K, Weber E, et al. The use of a new cell collector to isolate circulating tumor cells from the blood of patients with different stages of prostate cancer and clinical outcomes - a proof-of-concept study. PLoS One. 2016;11(8):e0158354. doi:10.1371/journal.pone.0158354

142. Chen N, Qin S, Yang X, Wang Q, Huang J, Wang K. "Sense-and-treat" DNA nanodevice for synergetic destruction of circulating tumor cells. ACS Appl Mater Interfaces. 2016;8(40):26552-26558. doi:10.1021/ acsami.6b08695

143. Li S, Jiang Q, Liu S, et al. A DNA nanorobot functions as a cancer therapeutic in response to a molecular trigger in vivo. Nat Biotechnol. 2018;36(3):258-264. doi:10.1038/nbt.4071

144. Chen N, Yang X, Wang Q, et al. Proof of concept for inhibiting metastasis: circulating tumor cell-triggered localized release of anticancer agent via a structure-switching aptamer. Chem Commun (Camb). 2016; 52(41):6789-6792. doi:10.1039/c6cc02374f
145. Medina SH, El-Sayed ME. Dendrimers as carriers for delivery of chemotherapeutic agents. Chem Rev. 2009;109(7):3141-3157. doi: $10.1021 / \mathrm{cr} 900174 \mathrm{j}$

146. Xie J, Dong H, Chen H, et al. Exploring cancer metastasis prevention strategy: interrupting adhesion of cancer cells to vascular endothelia of potential metastatic tissues by antibody-coated nanomaterial. J Nanobiotechnology. 2015;13:9. doi:10.1186/s12951-015-0072-x

147. Xie J, Gao Y, Zhao R, et al. Ex vivo and in vivo capture and deactivation of circulating tumor cells by dual-antibody-coated nanomaterials. JControl Release. 2015;209:159-169. doi:10.1016/j.jconrel.2015.04.036

148. Xie J, Zhao R, Gu S, et al. The architecture and biological function of dual antibody-coated dendrimers: enhanced control of circulating tumor cells and their hetero-adhesion to endothelial cells for metastasis prevention. Theranostics. 2014;4(12):1250-1263. doi:10.7150/thno.8775

149. Brandl A, Wagner T, Uhlig KM, et al. Dynamically regulated sumoylation of HDAC2 controls p53 deacetylation and restricts apoptosis following genotoxic stress. J Mol Cell Biol. 2012;4(5):284-293. doi:10.1093/jmcb/mjs013

150. Dong H, Han L, Wu Z-S, et al. Biostable Aptamer Rings Conjugated for Targeting Two Biomarkers on Circulating Tumor Cells in Vivo with Great Precision. Chem Mater. 2017;29(24):10312-10325.

151. Zheng F, Cheng Y, Wang J, et al. Aptamer-functionalized barcode particles for the capture and detection of multiple types of circulating tumor cells. Adv Mater. 2014;26(43):7333-7338. doi:10.1002/ adma.201403530

152. Wang $\mathrm{Y}$, Zhao Q, Han N, et al. Mesoporous silica nanoparticles in drug delivery and biomedical applications. Nanomedicine. 2015;11(2): 313-327. doi:10.1016/j.nano.2014.09.014

153. Gao Y, Gu S, Zhang Y, et al. The architecture and function of monoclonal antibody-functionalized mesoporous silica nanoparticles loaded with mifepristone: repurposing abortifacient for cancer metastatic chemoprevention. Small. 2016;12(19):2595-2608. doi:10.1002/ smll.201600550

154. Gao Y, Xie X, Li F, et al. A novel nanomissile targeting two biomarkers and accurately bombing CTCs with doxorubicin. Nanoscale. 2017;9(17):5624-5640. doi:10.1039/c7nr00273d

155. Pattni BS, Chupin VV, Torchilin VP. New developments in liposomal drug delivery. Chem Rev. 2015;115(19):10938-10966. doi:10.1021/ acs.chemrev.5b00046

156. Dai Z, Yue X. Liposomal nanotechnology for cancer theranostics. Curr Med Chem. 2018;25(12):1397-1408.

157. Fenske DB, Cullis PR. Liposomal nanomedicines. Expert Opin Drug Deliv. 2008;5(1):25-44. doi:10.1517/17425247.5.1.25

158. Yu HP, Aljuffali IA, Fang JY. Injectable drug-loaded nanocarriers for lung cancer treatments. Curr Pharm Des. 2017;23(3):481-494. doi:10. 2174/1381612822666161027113654

159. Muthu MS, Feng SS. Theranostic liposomes for cancer diagnosis and treatment: current development and pre-clinical success. Expert Opin Drug Deliv. 2013;10(2):151-155. doi:10.1517/17425247.2013. 729576

160. Mitchell MJ, Castellanos CA, King MR. Nanostructured surfaces to target and kill circulating tumor cells while repelling leukocytes. J Nanomater. 2012;2012:831263. doi:10.1155/2012/831263

161. Mitchell MJ, Chen CS, Ponmudi V, Hughes AD, King MR. E-selectin liposomal and nanotube-targeted delivery of doxorubicin to circulating tumor cells. J Control Release. 2012;160(3):609-617. doi:10.1016/j. jconrel.2012.02.018

162. Mahapatro A, Singh DK. Biodegradable nanoparticles are excellent vehicle for site directed in-vivo delivery of drugs and vaccines. J Nanobiotechnology. 2011;9:55. doi:10.1186/1477-3155-9-55

163. Peppas NA. Historical perspective on advanced drug delivery: how engineering design and mathematical modeling helped the field mature. Adv Drug Deliv Rev. 2013;65(1):5-9. doi:10.1016/j.addr.2012.09.040

164. Croy SR, Kwon GS. Polymeric micelles for drug delivery. Curr Pharm Des. 2006;12(36):4669-4684.

165. Jeong B, Bae YH, Lee DS, Kim SW. Biodegradable block copolymers as injectable drug-delivery systems. Nature. 1997;388(6645):860-862. doi: $10.1038 / 42218$ 
166. Patri AK, Majoros IJ, Baker JR. Dendritic polymer macromolecular carriers for drug delivery. Curr Opin Chem Biol. 2002;6(4):466-471.

167. Gaucher G, Dufresne MH, Sant VP, Kang N, Maysinger D, Leroux JC. Block copolymer micelles: preparation, characterization and application in drug delivery. J Control Release. 2005;109(1-3):169-188. doi:10.1016/j.jconrel.2005.09.034

168. Langer R, Folkman J. Polymers for the sustained release of proteins and other macromolecules. Nature. 1976;263(5580):797-800.

169. Sadat Tabatabaei Mirakabad F, Nejati-Koshki K, Akbarzadeh A, et al. PLGA-based nanoparticles as cancer drug delivery systems. Asian Pac J Cancer Prev. 2014;15(2):517-535.

170. Jain RA. The manufacturing techniques of various drug loaded biodegradable poly(lactide-co-glycolide) (PLGA) devices. Biomaterials. 2000;21(23):2475-2490.

171. Lu JM, Wang X, Marin-Muller C, et al. Current advances in research and clinical applications of PLGA-based nanotechnology. Expert Rev Mol Diagn. 2009;9(4):325-341. doi:10.1586/erm.09.15

172. Studer M, Briel M, Leimenstoll B, Glass TR, Bucher HC. Effect of different antilipidemic agents and diets on mortality: a systematic review. Arch Intern Med. 2005;165(7):725-730. doi:10.1001/archinte. 165.7 .725

173. Wickline SA, Neubauer AM, Winter PM, Caruthers SD, Lanza GM. Molecular imaging and therapy of atherosclerosis with targeted nanoparticles. J Magn Reson Imaging. 2007;25(4):667-680. doi:10. 1002/jmri.20866

174. Trivedi R, Kompella UB. Nanomicellar formulations for sustained drug delivery: strategies and underlying principles. Nanomedicine (Lond). 2010;5(3):485-505. doi:10.2217/nnm.10.10

175. Venkatraman SS, Jie P, Min F, Freddy BY, Leong-Huat G. Micellelike nanoparticles of PLA-PEG-PLA triblock copolymer as chemotherapeutic carrier. Int J Pharm. 2005;298(1):219-232. doi:10.1016/j. ijpharm.2005.03.023
176. Bisht S, Maitra A. Dextran-doxorubicin/chitosan nanoparticles for solid tumor therapy. Wiley Interdiscip Rev Nanomed Nanobiotechnol. 2009;1(4):415-425. doi:10.1002/wnan.43

177. Ye YQ, Yang FL, Hu FQ, Du YZ, Yuan H, Yu HY. Core-modified chitosan-based polymeric micelles for controlled release of doxorubicin. Int J Pharm. 2008;352(1-2):294-301. doi:10.1016/j.ijpharm.2007.10.035

178. Yao J, Feng J, Gao X, et al. Neovasculature and circulating tumor cells dual-targeting nanoparticles for the treatment of the highly-invasive breast cancer. Biomaterials. 2017;113:1-17. doi:10.1016/j.biomaterials. 2016.10.033

179. Luk BT, Zhang L. Cell membrane-camouflaged nanoparticles for drug delivery. J Control Release. 2015;220(Pt B):600-607. doi:10.1016/j. jconrel.2015.07.019

180. Meyer RA, Sunshine JC, Green JJ. Biomimetic particles as therapeutics. Trends Biotechnol. 2015;33(9):514-524. doi:10.1016/j.tibtech. 2015.07.001

181. Dehaini D, Fang RH, Zhang L. Biomimetic strategies for targeted nanoparticle delivery. Bioeng Transl Med. 2016;1(1):30-46. doi:10. 1002/btm2.10004

182. Hu Q, Sun W, Qian C, Wang C, Bomba HN, Gu Z. Anticancer platelet-mimicking nanovehicles. Adv Mater. 2015;27(44):7043-7050. doi:10.1002/adma.201503323

183. Li J, Ai Y, Wang L, et al. Targeted drug delivery to circulating tumor cells via platelet membrane-functionalized particles. Biomaterials. 2016;76:52-65. doi:10.1016/j.biomaterials.2015.10.046

184. Kang T, Zhu Q, Wei D, et al. Nanoparticles coated with neutrophil membranes can effectively treat cancer metastasis. ACS Nano. 2017; 11(2):1397-1411. doi:10.1021/acsnano.6b06477

185. He X, Cao H, Wang $\mathrm{H}$, et al. Inflammatory monocytes loading protease-sensitive nanoparticles enable lung metastasis targeting and intelligent drug release for anti-metastasis therapy. Nano Lett. 2017; 17(9):5546-5554. doi:10.1021/acs.nanolett.7b02330
International Journal of Nanomedicine

\section{Publish your work in this journal}

The International Journal of Nanomedicine is an international, peerreviewed journal focusing on the application of nanotechnology in diagnostics, therapeutics, and drug delivery systems throughout the biomedical field. This journal is indexed on PubMed Central,

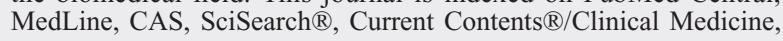

\section{Dovepress}

Journal Citation Reports/Science Edition, EMBase, Scopus and the Elsevier Bibliographic databases. The manuscript management system is completely online and includes a very quick and fair peer-review system, which is all easy to use. Visit http://www.dovepress.com/ testimonials.php to read real quotes from published authors. 